\title{
Debt and financial market contagion
}

\author{
Cody Yu-Ling Hsiao ${ }^{1,2}$ (D) James Morley ${ }^{3}$
}

Received: 9 September 2020 / Accepted: 21 May 2021 / Published online: 11 June 2021

(c) The Author(s), under exclusive licence to Springer-Verlag GmbH Germany, part of Springer Nature 2021

\begin{abstract}
We empirically investigate why financial crises spread from one country to another. For our analysis, we develop a new multiple-channel test of financial market contagion and construct indices of crisis severity in equity markets in order to examine how the transmission of shocks across countries can be related to direct linkages between countries or to common characteristics. Based on network analysis with our proposed multiple-channel test for crises between 2007 and 2021, we find that the Great Recession is the most pervasive across countries, followed by the European sovereign debt crisis and the recent COVID pandemic, with the subprime mortgage crisis being the least pervasive. Our main finding is that similar public, private and external debt characteristics are particularly helpful in explaining the transmission of financial shocks during crises. Fiscal deficits appear more important than current account deficits, while stage of economic development matters more than regional linkages, but none of these indicators is as important as debt.
\end{abstract}

Keywords Contagion - Debt · European debt crisis · Great recession · COVID . Regional linkages

JEL Classifications C51 · G01 · G15

\section{Introduction}

Recent crises have renewed interest in financial market contagion and its possible sources. Contagion can be broadly described as a trigger country suffering a negative shock that quickly spreads to other countries through numerous channels. Several stud-

$凶$ Cody Yu-Ling Hsiao

ylhsiao@must.edu.mo

1 School of Business, Macau University of Science and Technology, Macau, China

2 Centre for Applied Macroeconomic Analysis (CAMA), Australian National University, Canberra, Australia

3 School of Economics, University of Sydney, Camperdown, Australia 
ies have investigated financial market contagion (King and Wadhwani 1990; Forbes and Rigobon 2002; Bae et al. 2003; Fry et al. 2010; Keddad and Schalck 2020; Nitoi and Pochea 2020), although the exact definition and measurement of contagion varies considerably across studies.

The most commonly used definitions of financial market contagion are those proposed by King and Wadhwani (1990) and Forbes and Rigobon (2002), who focus on a comparison of the linear dependence structure across markets in non-crisis and crisis periods. However, instead of focusing on the correlation of returns, other researchers have considered alternative measures such as higher-order co-moments or tail dependencies to capture contagion. For instance, Favero and Giavazzi (2002) explore outlier tests, Bae et al. (2003) develop the co-exceedance approach based on extreme value theory, Pesaran and Pick (2007) and Finta et al. (2019) propose the threshold tests of contagion, Rodriguez (2007) and Silvapulle et al. (2016) study tail dependence using copulas, Fry et al. (2010) introduce the co-skewness change tests, and Fry-McKibbin and Hsiao (2018) developed the co-kurtosis and co-volatility change tests. This literature examines contagion by focusing primarily on single-channel tests, which may not capture all relevant dependencies across financial markets. Moreover, as we show, single-channel tests based on changes in correlation (Forbes and Rigobon 2002), co-skewness (Fry et al. 2010), or co-kurtosis and co-volatility (Fry-McKibbin and Hsiao 2018) have some size distortions when the sample period for a crisis episode is relatively short compared to non-crisis periods. The most closely related paper is FryMcKibbin et al. (2021) who study the entropy theory through second- and higher-order co-moments, but focus on measuring market interdependence rather than contagion.

Instead of just focusing on a single-channel test of contagion, we introduce a new multiple-channel test for which the effects of a financial crisis can be identified not only through a change in correlation, but also through changes in higher-order comoments. ${ }^{1}$ Following Forbes and Rigobon (2002), we define contagion as a significant change in a co-moment relative to what would be expected given heteroskasticity. However, our proposed test enables us to capture changes in various aspects of dependency across asset returns, specifically correlation (how the mean return in one country depends on the return in another), co-skewness (how the volatility in one country depends on the return in another) and co-volatility (how the volatility in one country depends on the volatility in another). Our formal test is based on a Lagrange multiplier statistic constructed under the hypothesis of no change in co-moments relative to what would be expected given heteroskasticity and we derive its distribution allowing for the presence of a non-normal multivariate return distribution, as is appropriate for financial time series.

In addition to providing a more comprehensive test for contagion that captures linear, asymmetric and tail dependencies simultaneously, we also directly consider why financial crises spread across countries. Several possible explanations have been investigated in the literature, including trade linkages ( Van Rijckeghem and Weder 2001; Kali and Reyes 2010; Ters and Urban 2018, financial linkages (Ahlgren and Antell 2010), regional proximity to the market in which the crisis originates (Glick

\footnotetext{
1 Fry-McKibbin et al. (2019) consider a multiple-channel test of contagion, but the channels correspond to higher-order co-moments only.
} 
and Rose 1999), comparably stage of economic development (Fry-McKibbin et al. 2014), external and internal imbalances (Caramazza et al. 2004; Ehrmann et al. 2009; Bekaert et al. 2011), as well as government debt (Reinhard and Rogoff 2011; Forbes (2012)) and fiscal conditions (Dioikitopoulos 2018; Niemann and Pichler 2020). We focus on which similar pre-crisis characteristics, including levels of different types of debt, regional linkages and stage of development, are the most important in explaining the likelihood of contagion. ${ }^{2}$ The importance of these characteristics is determined by grouping countries by characteristic and comparing a measure of crisis severity in terms of frequency of significant contagion from a crisis for each country grouping.

Our main results can be summarized as follows: First, among the four financial crises from 2007 to 2021 (the subprime mortgage crisis, the Great Recession crisis, the European sovereign debt crisis and the coronavirus disease (COVID) crisis), the crises associated with Great Recession seems from our proposed multiple-channel test and network analysis to have been the most pervasive across countries, followed by the European sovereign debt crisis and the COVID pandemic, with the subprime mortgage crisis being the least pervasive. Second, debt conditions (public, private and external debt) were the most important determinants in explaining the transmission of financial shocks during crises. The current account balance did not necessarily alter crisis transmission, while the evidence indicates that government fiscal balance was only somewhat correlated with contagion during the crises. Third, compared with stage of development, regional linkages were a weak predictor of contagion during the financial crises. Only the European sovereign debt and, to some extent, the COVID crises had evidence of regional contagion, as might be expected, but contagion with the subprime mortgage crisis and the Great Recession crisis did not seem at all to be regionally determined.

The rest of this paper proceeds are follows. Section 2 describes the single- and multiple-channel tests of contagion considered in our analysis and considers their finite-sample properties. The tests are then applied in Sect. 3 to investigate financial market contagion during the four crises from 2007 to 2021. Section 4 concludes.

\section{Contagion tests}

This section provides details of the Lagrange multiplier tests of contagion used in our analysis. Following the work of Fry et al. (2010) and Fry-McKibbin and Hsiao (2018), the bivariate generalized exponential family of the distribution for the two random variables $r_{1, t}$ and $r_{2, t}$ at time $t$ is

$$
f\left(r_{1, t}, r_{2, t}\right)=\exp \left(h_{t}-\eta_{t}\right)
$$

\footnotetext{
2 To be clear, we consider contagion across equity markets based on debt characteristics rather than contagion across bond markets, such as considered in Gravelle et al. (2006).
} 
where $h_{t}$ specified as bivariate normal distribution through the first- to the fourth-order co-moments gives

$$
\begin{aligned}
h_{t}= & -\frac{1}{2}\left(\frac{1}{1-\rho^{2}}\right)\left(\left(\frac{r_{1, t}-\mu_{1}}{\sigma_{2}}\right)^{2}+\left(\frac{r_{2, t}-\mu_{2}}{\sigma_{2}}\right)^{2}-2 \rho\left(\frac{r_{1, t}-\mu_{1}}{\sigma_{1}}\right)\left(\frac{r_{2, t}-\mu_{2}}{\sigma_{2}}\right)\right) \\
& +\theta_{4}\left(\frac{r_{1, t}-\mu_{1}}{\sigma_{1}}\right)\left(\frac{r_{2, t}-\mu_{2}}{\sigma_{2}}\right)^{2}+\theta_{5}\left(\frac{r_{1, t}-\mu_{1}}{\sigma_{1}}\right)^{2}\left(\frac{r_{2, t}-\mu_{2}}{\sigma_{2}}\right) \\
& +\theta_{6}\left(\frac{r_{1, t}-\mu_{1}}{\sigma_{1}}\right)^{2}\left(\frac{r_{2, t}-\mu_{2}}{\sigma_{2}}\right)^{2}-\eta_{t},
\end{aligned}
$$

and $\eta_{t}$ is the normalizing constant

$$
\eta_{t}=\ln \iint \exp \left(h_{t}\right) d r_{1} d r_{2}
$$

The distribution in (1) is an extension of the univariate generalized distribution by Cobb et al. (1983) and Lye and Martin (1993). The choice of $h_{t}$ corresponds to polynomials and cross-products of standard scores for the two random variables $r_{1}$ and $r_{2}$. The parameter $\rho$ controls the degree of linear dependence (correlation), the parameters $\theta_{4}$ and $\theta_{5}$ control the asymmetric dependencies (co-skewness) and the parameter $\theta_{6}$ control the extremal dependencies (co-volatility). In a special case, the distribution in (1) reduces to a bivariate normal distribution if $\theta_{4}, \theta_{5}$ and $\theta_{6}$ in (2) are equal to zero.

We develop a Lagrange multiplier statistic to test joint co-moments. Giving a sample of size $T$, the log-likelihood function corresponding to (1) is of the form

$$
\ln L(\Theta)=\frac{1}{T} \sum_{t=1}^{T} h_{t}(\Theta)-\frac{1}{T} \sum_{t=1}^{T} \eta_{t}(\Theta)
$$

where $\Theta=\left(\theta_{1}, \ldots, \theta_{K}\right)^{\prime}$ is a finite number $K$ of the unknown parameters. The hypothesis to be tested is specified as $H_{0}: \theta_{1}=0, \ldots, \theta_{p}=0 ; p \leq K$. The Lagrange multiplier test statistic is given by

$$
L M=T S(\widehat{\Theta})^{\prime} I(\widehat{\Theta})^{-1} S(\widehat{\Theta})
$$

where $\widehat{\Theta}$ represent the maximum likelihood estimator of $\Theta$ under the null hypothesis and $S(\widehat{\Theta})$ is the score function evaluated at $\widehat{\Theta}$ given by

$$
S(\widehat{\Theta})=\left(\frac{\partial \ln L(\Theta)}{\partial \Theta}\right) \mid \Theta=\widehat{\Theta},
$$


and $I(\widehat{\Theta})$ is the asymptotic information matrix evaluated at $\widehat{\Theta}$, which is derived by Fry et al. (2010), given by

$$
I(\widehat{\Theta})=\left(E\left[\frac{\partial h_{t}}{\partial \Theta} \frac{\partial h_{t}}{\partial \Theta^{\prime}}\right]-E\left[\frac{\partial h_{t}}{\partial \Theta}\right] E\left[\frac{\partial h_{t}}{\partial \Theta^{\prime}}\right]\right) \mid \Theta=\widehat{\Theta} .
$$

Under the null hypothesis, the Lagrange multiplier test statistic is asymptotically distributed as $\chi_{p}^{2}$, where $p$ is the number of constraints imposed under the null hypothesis. The advantage of using this test is that the Lagrangian multiplier test does not require the estimation of the unrestricted model as the distribution in (1) is nested in the bivariate normal distribution by setting the restrictions $\theta_{4}=\theta_{5}=\theta_{6}=0$. The existing contagion literature using Lagrange multiplier tests includes the co-skewness statistics of Fry et al. (2010), the co-kurtosis and co-volatility statistics of Fry-McKibbin and Hsiao (2018) and joint statistics of co-skewness, co-kurtosis and co-volatility of Fry-McKibbin et al. (2019). The full derivations behind our multiple-channel test statistic for correlation, co-skewness and co-volatility are given in Appendix B and Appendix C.

In developing our test of contagion, the following notation is used. The pre-crisis period is denoted as $x$, and the crisis period is denoted as $y$. The sample sizes of the pre-crisis and crisis periods are $T_{x}$ and $T_{y}$, respectively. The correlation between the two asset returns is denoted as $\rho_{x}$ (pre-crisis) and $\rho_{y}$ (crisis). The source crisis market is denoted as $i$, and the recipient market is denoted as $j$. Finally, $\widehat{\mu}_{i x}, \widehat{\mu}_{j x}, \widehat{\mu}_{i y}$ and $\widehat{\mu}_{j y}$ are the sample means of the asset returns for markets $i$ and $j$ during the two periods, and $\widehat{\sigma}_{i x}, \widehat{\sigma}_{j x}, \widehat{\sigma}_{i y}$ and $\widehat{\sigma}_{j y}$ are the sample standard deviations of the asset returns for markets $i$ and $j$ during the two periods.

\subsection{Single-channel tests}

The existing contagion tests in the literature tend to focus on individual channels for contagion. Four types of single-channel tests are considered here. The first is the Forbes and Rigobon (2002) correlation change test where it is based on changes in correlation. The second and third are Fry et al. (2010) co-skewness change tests where they are based on changes in co-skewness. The final is Fry-McKibbin and Hsiao (2018) co-volatility change test based on changes in co-volatility.

\subsubsection{Correlation test}

The first type of single-channel contagion test developed by Fry et al. (2010) extends early forms of the correlation contagion tests of Forbes and Rigobon (2002). The test statistic is based on significance change in the adjusted crisis period correlation $\left(\widehat{v}_{y \mid x_{i}}\right)$ compared to a pre-crisis period correlation $\left(\widehat{\rho}_{x}\right)$ given by

$$
S T_{1: 1}(i \rightarrow j)=\left(\frac{\widehat{v}_{y \mid x_{i}}-\widehat{\rho}_{x}}{\sqrt{\operatorname{Var}\left(\widehat{v}_{y \mid x_{i}}-\widehat{\rho}_{x}\right)}}\right)^{2},
$$


where $\widehat{v}_{y \mid x_{i}}$ is the heteroskedasticity adjusted correction coefficient derived by Forbes and Rigobon (2002) given by

$$
\widehat{v}_{y \mid x_{i}}=\frac{\widehat{\rho}_{y}}{\sqrt{1+\left(\left(\widehat{\sigma}_{i y}^{2}-\widehat{\sigma}_{i x}^{2}\right) / \widehat{\sigma}_{i x}^{2}\right)\left(1-\widehat{\rho}_{y}^{2}\right)}} .
$$

The standard error for (8) is presented in Fry et al. (2010), where

$$
\begin{aligned}
\operatorname{Var}\left(\widehat{v}_{y \mid x_{i}}-\widehat{\rho}_{x}\right)= & \operatorname{Var}\left(\widehat{v}_{y \mid x_{i}}\right)+\operatorname{Var}\left(\widehat{\rho}_{x}\right)-2 \operatorname{Cov}\left(\widehat{v}_{y \mid x_{i}}, \widehat{\rho}_{x}\right), \\
\operatorname{Var}\left(\widehat{v}_{y \mid x_{i}}\right)= & \frac{1}{2} \frac{\left(1+\left(\left(\widehat{\sigma}_{i y}^{2}-\widehat{\sigma}_{i x}^{2}\right) / \widehat{\sigma}_{i x}^{2}\right)\right)^{2}}{\left[1+\left(\left(\widehat{\sigma}_{i y}^{2}-\widehat{\sigma}_{i x}^{2}\right) / \widehat{\sigma}_{i x}^{2}\right)\left(1-\widehat{\rho}_{y}^{2}\right)\right]^{3}} \times \\
& {\left[\frac{1}{T_{y}}\left(\left(2-\widehat{\rho}_{y}^{2}\right)\left(1-\widehat{\rho}_{y}^{2}\right)^{2}\right)+\frac{1}{T_{x}}\left(\widehat{\rho}_{y}^{2}\left(1-\widehat{\rho}_{y}^{2}\right)^{2}\right)\right], } \\
\operatorname{Var}\left(\widehat{\rho}_{x}\right)= & \frac{1}{T_{x}}\left(1-\widehat{\rho}_{x}^{2}\right)^{2}, \\
\operatorname{Cov}\left(\widehat{v}_{y \mid x_{i}}, \widehat{\rho}_{x}\right)= & \frac{1}{2} \frac{1}{T_{x}} \frac{\widehat{\rho}_{y} \widehat{\rho}_{x}\left(1-\widehat{\rho}_{y}^{2}\right)\left(1-\widehat{\rho}_{x}^{2}\right)\left(1+\left(\left(\widehat{\sigma}_{i y}^{2}-\widehat{\sigma}_{i x}^{2}\right) / \widehat{\sigma}_{i x}^{2}\right)\right)}{\sqrt{\left[1+\left(\left(\widehat{\sigma}_{i y}^{2}-\widehat{\sigma}_{i x}^{2}\right) / \widehat{\sigma}_{i x}^{2}\right)\left(1-\rho_{y}^{2}\right)\right]^{3}}}
\end{aligned}
$$

\subsubsection{Co-skewness tests}

The second and third single-channel tests are the co-skewness tests proposed by Fry et al. (2010). The tests are based on the significance change in the crisis co-skewness coefficient $\left(\widehat{\psi}_{y}\right)$ compared to the pre-crisis period co-skewness coefficient $\left(\widehat{\psi}_{x}\right)$ given as

$$
\begin{aligned}
S T_{1: 2}(i \rightarrow j) & =\left(\frac{\widehat{\psi}_{y}\left(r_{i}^{1}, r_{j}^{2}\right)-\widehat{\psi}_{x}\left(r_{i}^{1}, r_{j}^{2}\right)}{\sqrt{\frac{4 \widehat{v}_{y \mid x_{i}}^{2}+2}{T_{y}}+\frac{4 \widehat{\rho}_{x}^{2}+2}{T_{x}}}}\right)^{2}, \\
S T_{2: 1}(i \rightarrow j) & =\left(\frac{\widehat{\psi}_{y}\left(r_{i}^{2}, r_{j}^{1}\right)-\widehat{\psi}_{x}\left(r_{i}^{2}, r_{j}^{1}\right)}{\sqrt{\frac{4 \widehat{v}_{y \mid x_{i}}^{2}+2}{T_{y}}+\frac{4 \widehat{\rho}_{x}^{2}+2}{T_{x}}}}\right)^{2},
\end{aligned}
$$


where two forms of co-skewness moments during the pre-crisis $(x)$ and crisis $(y)$ periods be

$$
\begin{aligned}
& \widehat{\psi}_{x}\left(r_{i}^{a}, r_{j}^{b}\right)=\frac{1}{T_{x}} \sum_{t=1}^{T_{x}}\left(\frac{r_{i, t}-\widehat{\mu}_{i x}}{\widehat{\sigma}_{i x}}\right)^{a}\left(\frac{r_{j, t}-\widehat{\mu}_{j x}}{\widehat{\sigma}_{j x}}\right)^{b}, \\
& \widehat{\psi}_{y}\left(r_{i}^{a}, r_{j}^{b}\right)=\frac{1}{T_{y}} \sum_{t=1}^{T_{y}}\left(\frac{r_{i, t}-\widehat{\mu}_{i y}}{\widehat{\sigma}_{i y}}\right)^{a}\left(\frac{r_{j, t}-\widehat{\mu}_{j y}}{\widehat{\sigma}_{j y}}\right)^{b},
\end{aligned}
$$

where $a=1, b=2$ is the first form of co-skewness and $a=2, b=1$ is the second form of co-skewness. The first form of $S T_{1: 2}$ is a test for contagion through new spillover from the level returns of the source country $i$ to the squared return of the recipient country $j$. The second form of $S T_{2: 1}$ is a test for contagion through new spillover from the squared returns of the source country $i$ to the level returns of the recipient country $j$.

\subsubsection{Co-volatility test}

The final single-channel test is the co-volatility contagion test developed by FryMcKibbin and Hsiao (2018). The test is based on the significance change in the crisis co-volatility coefficient $\left(\widehat{\xi}_{y}\left(r_{i}^{2}, r_{j}^{2}\right)\right)$ compared to the pre-crisis co-volatility coefficient $\left(\widehat{\xi}_{x}\left(r_{i}^{2}, r_{j}^{2}\right)\right)$ given by

$$
S T_{2: 2}(i \rightarrow j)=\left(\frac{\widehat{\xi}_{y}\left(r_{i}^{2}, r_{j}^{2}\right)-\widehat{\xi}_{x}\left(r_{i}^{2}, r_{j}^{2}\right)}{\sqrt{\frac{4 \widehat{v}_{y \mid x_{i}}^{4}+16 \widehat{v}_{y \mid x_{i}}^{2}+4}{T_{y}}+\frac{4 \widehat{\rho}_{x}^{4}+16 \widehat{\rho}_{x}^{2}+4}{T_{x}}}}\right)^{2}
$$

where

$$
\begin{aligned}
& \widehat{\xi}_{y}\left(r_{i}^{2}, r_{j}^{2}\right)=\frac{1}{T_{y}} \sum_{t=1}^{T_{y}}\left(\frac{y_{i, t}-\widehat{\mu}_{i y}}{\widehat{\sigma}_{i y}}\right)^{2}\left(\frac{y_{j, t}-\widehat{\mu}_{j y}}{\widehat{\sigma}_{j y}}\right)^{2}-\left(1+2 \widehat{\nu}_{y \mid x_{i}}^{2}\right), \\
& \widehat{\xi}_{x}\left(r_{i}^{2}, r_{j}^{2}\right)=\frac{1}{T_{x}} \sum_{t=1}^{T_{x}}\left(\frac{x_{i, t}-\widehat{\mu}_{i x}}{\widehat{\sigma}_{i x}}\right)^{2}\left(\frac{x_{j, t}-\widehat{\mu}_{j x}}{\widehat{\sigma}_{j x}}\right)^{2}-\left(1+2 \widehat{\rho}_{x}^{2}\right) .
\end{aligned}
$$

(15) and (16) are the demeaned fourth-order co-moments during pre-crisis and crisis periods, respectively. The $S T_{2: 2}$ is a test for contagion through new spillover from the squared returns of the crisis country $i$ to the squared returns of the recipient country $j$. Under the null hypothesis of no contagion, the test statistics are asymptotically distributed as $S T_{1: 1}, S T_{1: 2}, S T_{2: 1}, S T_{2: 2} \stackrel{d}{\longrightarrow} \chi_{1}^{2}$. 


\subsection{Multiple-channel test}

The new contagion test developed in this paper involves a more general statistic, as it is designed to identify contagion through changes in multiple channels of correlation, both forms of co-skewness and co-volatility. The statistic $(M T)$ is designed to test for contagion from country $i$ to country $j$ (see Appendix C for details):

$$
\begin{gathered}
M T(i \rightarrow j)=\left(\frac{\widehat{v}_{y \mid x_{i}}-\widehat{\rho}_{x}}{\sqrt{\frac{1}{T_{x}}+\frac{1}{T_{y}}}}\right)^{2}+\left(\frac{\widehat{\psi}_{y}\left(r_{i}^{1}, r_{j}^{2}\right)-\widehat{\psi}_{x}\left(r_{i}^{1}, r_{j}^{2}\right)}{\sqrt{\frac{2}{T_{x}}+\frac{2}{T_{y}}}}\right)^{2} \\
+\left(\frac{\widehat{\psi}_{y}\left(r_{i}^{2}, r_{j}^{1}\right)-\widehat{\psi}_{x}\left(r_{i}^{2}, r_{j}^{1}\right)}{\sqrt{\frac{2}{T_{x}}+\frac{2}{T_{y}}}}\right)^{2}+\left(\frac{\widehat{\psi}_{y}\left(r_{i}^{2}, r_{j}^{2}\right)-\widehat{\psi}_{x}\left(r_{i}^{2}, r_{j}^{2}\right)}{\sqrt{\frac{4}{T_{x}}+\frac{4}{T_{y}}}}\right)^{2},
\end{gathered}
$$

where $\widehat{v}_{y \mid x_{i}}$ is the heteroskedasticity adjusted correction coefficient in equation (9), $a=1, b=2$ is the first form of co-skewness, and $a=2, b=1$ is the second form of co-skewness during the pre-crisis and crisis periods in equations (12) and (13), and $a=2, b=2$ is the co-volatility during the two periods in equations (15) and (16). The statistic $M T$ consists of four components capturing correlation, both forms of co-skewness and co-volatility simultaneously. Under the null hypothesis of no contagion, the test statistic in (17) is asymptotically distributed as $M T \stackrel{d}{\longrightarrow} \chi_{4}^{2}$, where the number of degrees of freedom is determined by the number of restrictions imposed on (2) under the null hypothesis which for this class of tests is $\rho=\theta_{4}=\theta_{5}=\theta_{6}=0$.

Table 1 summarizes the different single- and multiple-channel tests.

\subsection{Finite-sample properties}

We study the finite-sample properties of the single- and multiple-channel tests in the context of a relatively large pre-crisis sample size but relatively short crisis sample size, which is the standard setting for most financial market crises. To investigate this issue, the finite-sample distribution properties of the contagion tests under the null hypothesis of no contagion are conducted through simulations. The data generating process is based on the bivariate generalized normal distribution in (1), setting that the population means and variances at $\mu=0$, and $\sigma^{2}=1$, as well as the null hypothesis of no contagion is $\rho=\theta_{4}=\theta_{5}=\theta_{6}=0$. The joint density function is

$$
f\left(r_{1}, r_{2}\right)=\exp \left(-\frac{1}{2}\left(r_{1}^{2}+r_{2}^{2}\right)-\eta\right)
$$

where $\eta$ is the normalizing constant such that $\iint f\left(r_{1}, r_{2}\right) d r_{1} d r_{2}=1$. To allow for varying crisis period sample sizes, nine experiments are conducted, with the non-crisis sample size set to 500 days $\left(T_{x}\right)$ and the crisis period sample size varying from 30 to 500 days $\left(T_{y}=30,60,90,120,150,200,300,400,500\right)$. 


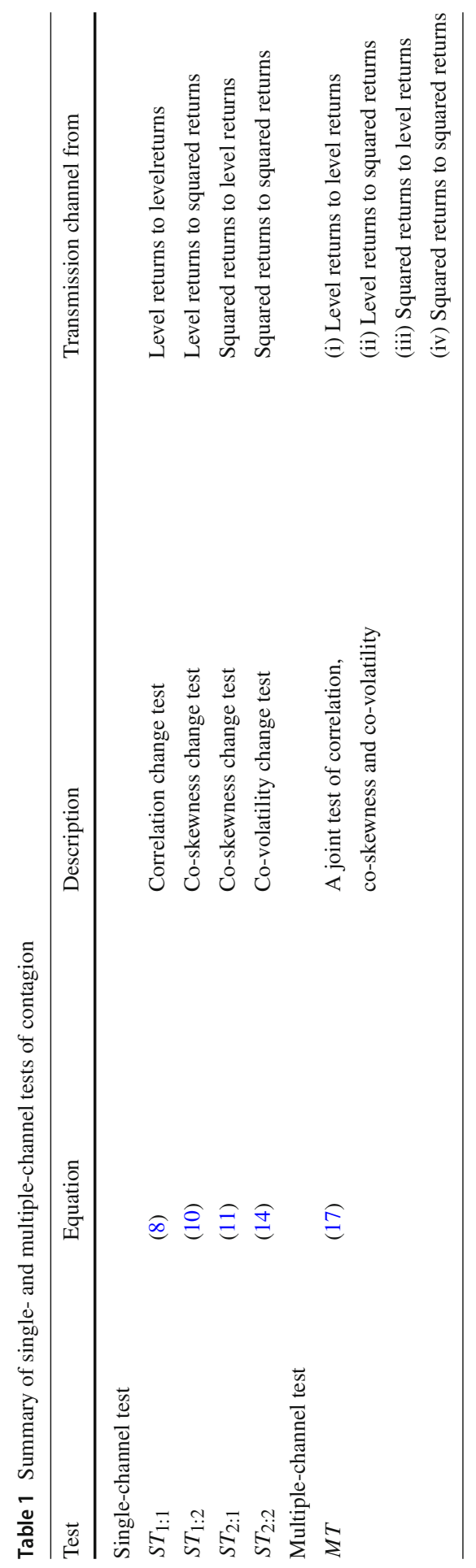


Table 2 Empirical size of alternative contagion tests based on the different lengths of the crisis period sample size $T_{y}$

\begin{tabular}{llllllllll}
\hline Tests & \multicolumn{7}{l}{ Sample size of crisis period $\left(T_{y}\right)$} \\
\cline { 2 - 9 } & 500 & 400 & 300 & 200 & 150 & 120 & 90 & 60 & 30 \\
\hline$S T_{1: 1}$ & 0.052 & 0.053 & 0.052 & 0.052 & 0.054 & 0.056 & 0.057 & 0.062 & 0.080 \\
$S T_{1: 2}$ & 0.050 & 0.051 & 0.049 & 0.046 & 0.049 & 0.047 & 0.046 & 0.044 & 0.038 \\
$S T_{2: 1}$ & 0.049 & 0.049 & 0.049 & 0.051 & 0.050 & 0.047 & 0.048 & 0.042 & 0.039 \\
$S T_{2: 2}$ & 0.047 & 0.049 & 0.048 & 0.046 & 0.042 & 0.042 & 0.037 & 0.033 & 0.019 \\
$M T$ & 0.053 & 0.053 & 0.052 & 0.053 & 0.054 & 0.054 & 0.054 & 0.054 & 0.056 \\
\hline
\end{tabular}

The pre-crisis sample size is $T_{x}=500$. The empirical size of the $S T_{1: 1}, S T_{1: 2}, S T_{2: 1}$ and $S T_{2: 2}$ tests is based on the $5 \%$ asymptotic $\chi_{1}^{2}$ critical values with 1 degree of freedom and the $M T$ test is based on the $5 \%$ asymptotic $\chi_{4}^{2}$ critical values with 4 degrees of freedom. The results are based on 50,000 replications

Table 2 reports results for the empirical size of the contagion tests as the duration of the crisis period $T_{y}$ is decreased from 500 to 30 days. The duration of the precrisis period is set to $T_{x}=500$ days. The number of replications is 50,000 for all simulations in order to minimize the effect of any simulation error on our inferences. ${ }^{3}$ The empirical size for the $S T_{1: 1}, S T_{1: 2}, S T_{2: 1}$ and $S T_{2: 2}$ tests is based on the $5 \%$ asymptotic $\chi_{1}^{2}$ distribution critical value, but for the $M T$ test is based on the $5 \%$ asymptotic $\chi_{4}^{2}$ distribution critical value.

The results show that given a relatively large pre-crisis sample size $\left(T_{x}=500\right)$, but relatively short crisis period sample size $\left(T_{y}=30\right)$, the proposed $M T$ test provides a good approximation of the finite-sample distribution among the five contagion tests, with the empirical size being close to the nominal size of 5\%. Given larger crisis period sample sizes, the remaining tests $\left(S T_{1: 1}, S T_{1: 2}, S T_{2: 1}\right.$ and $\left.S T_{2: 2}\right)$ exhibit the correct size of $5 \%$. However, if the crisis sample size is short $\left(T_{y}=30\right)$, the $S T_{1: 2}, S T_{2: 1}$ and $S T_{2: 2}$ tests are slightly undersized with values of $3.8 \%, 3.9 \%$ and $1.9 \%$, respectively, but the $S T_{1: 1}$ test is slightly oversized with value of $8.0 \%$.

\section{Application to four episodes of crisis}

\subsection{Data}

To investigate the impact of the four financial crises on equity markets of different countries around the world, we consider daily equity price indices for 44 countries during the 2005 to 2021 period collected from Datastream and Bloomberg database. ${ }^{4}$

\footnotetext{
3 Results would be mostly the same to three decimals given only 25,000 simulations.

4 The equity indices, expressed in US dollars, are collected from Datastream. The mneumonics are: Argentina - Argentina Merval price index; Australia - ASX200 price index; Austria - MSCI Austria price index; Belgium - BEL20 price index; Brazil - MSCI Brazilian price index; Bulgaria - Bulgaria Se Sofix price index; Canada - S\&P Composite price index; Chile - Chile Santiago Se General price index; China - Shanghai Se A Share price index; Colombia - Colombia IGBC price index; Denmark - OMX Copenhagen price index; Finland - OMX Helsinki price index; France - CAC40 price index; Germany - MDAX
} 
Table 3 Crisis and pre-crisis period dates

\begin{tabular}{llll}
\hline Crisis and non-crisis periods & Start of period & End of period & Source \\
\hline $\begin{array}{c}\text { (i) Crisis period dates } \\
\text { Subprime mortgage }\left(T_{1, y}\right)\end{array}$ & Jul 26, 2007 & Sep 14, 2009 & USA \\
Great Recession $\left(T_{2, y}\right)$ & Sep 15, 2009 & Dec 31, 2009 & USA \\
European debt $\left(T_{3, y}\right)$ & Jan 1, 2010 & Dec 31, 2013 & Greece \\
COVID $\left(T_{4, y}\right)$ & Dec 31, 2019 & Mar 17, 2021 & China \\
(ii) Pre-crisis dates & & & \\
Pre subprime mortgage $\left(T_{1, x}\right)$ & 1 Jan, 2005 & 25 Jul, 2007 & 30 Dec, 2019 \\
Pre COVID $\left(T_{2, x}\right)$ & 1 Jan, 2018 & & \\
\hline
\end{tabular}

The 44 countries are classified into four regions: Africa, Americas, Asia and Europe, which we consider to investigate contagion through the regional linkages. ${ }^{5}$

Daily percentage equity returns $\left(R_{l, t}\right)$ for the $l$ th market are calculated as

$$
R_{l, t}=100\left(\ln \left(P_{l, t}\right)-\ln \left(P_{l, t-1}\right)\right)
$$

where $P_{l, t}$ is the equity index in market $l$ at time $t$. Our sample period starts on January 1, 2005, and ends on March 17, 2021, which covers four episodes of financial crisis: (i) the subprime mortgage crisis, (ii) the Great Recession, (iii) the European debt crisis and iv) the recent COVID pandemic. ${ }^{6}$ According to Fry-McKibbin et al. (2014), the pre-crisis period is from January 1, 2005, to July 25, $2007\left(T_{1, x}=661\right.$ observations), while the crisis period is from July 26, 2007, to December 31, 2013 ( $T_{y}=1680$ observations). ${ }^{7}$ The subprime mortgage crisis coincides with heightened

Footnote 4 continued

Frankfurt price index; Greece - Athex Composite price index; Hong Kong - Hang Seng price index; Hungary - Budapest price index; India - CNX500 price index; Indonesia - IDX Composite price index; Ireland - Ireland Se Overall price index; Italy - FTSE MIB price index; Japan - NIKKEI225 Stock Average price index; Korea - Korea Se Composite price index; Malaysia - FTSE Bursa Malaysia Klci price index; Mexico - Mexico IPC price index; Netherlands - AEX price index; New Zealand - MSCI New Zealand price index; Norway - MSCI Norway price index; Peru - MSCI Peru price index; Philippines -PSEI price index; Poland - MSCI Poland price index; Portugal - MSCI Portugal price index; Romania - Romania Bet price index; Russia - Russia RTS price index; Singapore - MSCI Singapore price index; South Africa - FTSE All Share price index; Spain - IBEX35 price index; Sweden - OMX Stockholm price index; Switzerland Swiss Market price index; Taiwan - Taiwan Se Weighed price index; Thailand - Bangkok SET price index; Turkey - MSCI Turkey price index; UK - FTSE100 price index; USA - Dow Jones industrials price index.

5 The country in the African region is South Africa. The 8 countries in the Americas region are Argentina, Brazil, Canada, Chile, Colombia, Mexico, Peru and the USA. The 13 countries in the Asian region are Australia, China, Hong Kong, India, Indonesia, Japan, Korea, Malaysia, New Zealand, Philippines, Singapore, Taiwan and Thailand. The 22 countries in the European region are Austria, Belgium, Bulgaria, Denmark, Finland, France, Germany, Greece, Hungary, Ireland, Italy, Netherlands, Norway, Poland, Portugal, Romania, Russia, Spain, Sweden, Switzerland, Turkey and the UK.

6 The subprime mortgage crisis and Great Recession are separated by the severity of the collapse of Lehman Brothers on 15 September of 2008, and the Great Recession and European debt crisis are separated by the Greek bailout in the first quarter of 2010 .

7 In order to avoid arbitrary selection of the pre-crisis and crisis periods, we consider Bai and Perron (2003) structural break tests to identify the non-crisis and crisis dates. These tests support the dates specified in 

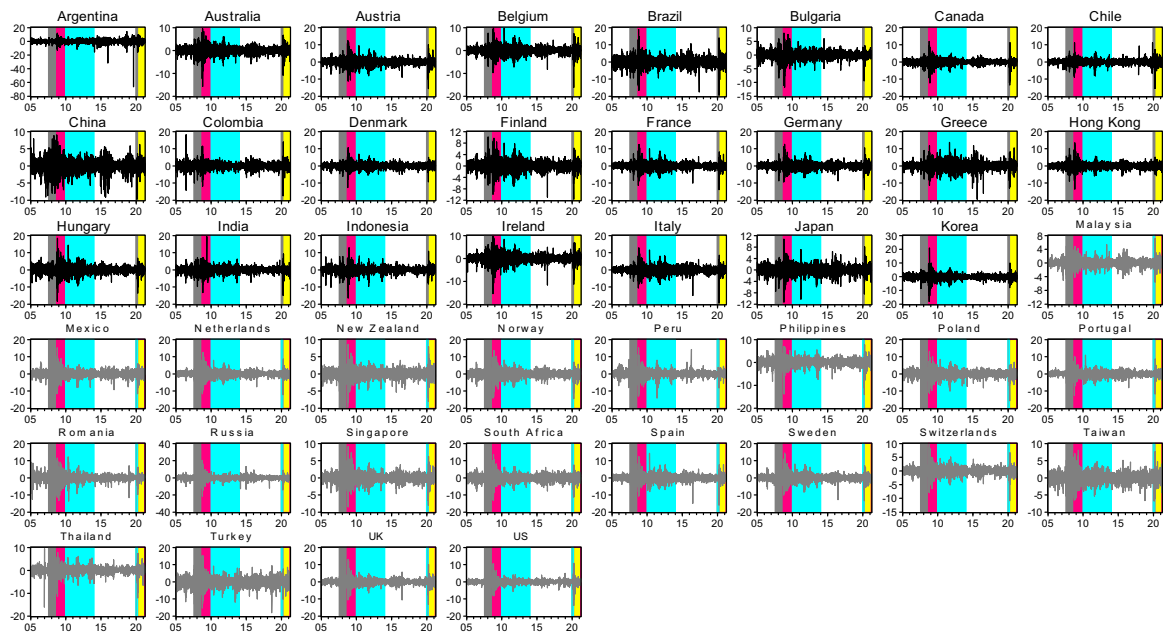

Fig. 1 Daily percentage returns of equity markets for 44 countries during the period of 2005 to 2021. The shaded areas refer to four episodes of financial crisis. These are the subprime mortgage crisis (July 26, 2007 to September 14, 2009), the Great Recession crisis (September 15, 2009 to December 31, 2009), the European debt crisis (January 1, 2010 to December 31, 2013) and the COVID pandemic (December 31, 2019 to March 17, 2021)

risk aversion and liquidity issues from July 26, 2007, to September 14, $2008\left(T_{1, y}=\right.$ 297 observations). The Great Recession crisis corresponds to September 15, 2008, to December 31, 2009 ( $T_{2, y}=339$ observations). The European debt crisis corresponds to January 1, 2010, to December 31, 2013 ( $T_{3, y}=1044$ observations). As the World Health Organization (WHO) announces the first official case of COVID in China on December 30, 2019, the pre-COVID period is defined from January 1, 2018, to December 30, $2019\left(T_{2, x}=514\right)$, and the COVID period is from December 31, 2019, to March 17, $2021\left(T_{4, y}=317\right)$, which is the most recent period available at the time of writing. ${ }^{8}$ The crisis source for the subprime mortgage crisis and the Great Recession crisis is assumed to be the USA (Chan et al. 2019). For the European debt crisis, the crisis source is assumed to be Greece (Beirne and Fratzscher 2013; Samarakoon 2017), and for the COVID pandemic, the crisis source is assumed to be China (Akhtaruzzaman et al. 2021). Table 3 summarizes the dates for each crisis episode and its crisis source. All returns are plotted in Fig. 1, showing that the returns volatility changes dramatically around the world during the crisis periods compared with the pre-crisis periods.

To highlight changes in the behavior of equity returns between pre-crisis and crisis periods, Table 4 reports descriptive statistics of the own-moments of the mean, standard deviation, skewness and kurtosis of equity returns in each country during

\section{Footnote 7 continued}

Fry-McKibbin et al. (2014). We also perform the sensitivity analysis by taking the dates as one-month before and after the structural break on July 25, 2007 for robustness. These structural break and robustness test results are provided in Appendix D.

8 We filter the data in the same way as in Forbes and Rigobon (2002). Before conducting the contagion tests, a vector autoregressive (VAR) model is used to control for market fundamentals (country-specificand 
the pre-crisis (January 1, 2005 to July 25, 2007) and crisis (September 15, 2008 to December 31, 2009) periods. The first and second moments show that average returns (mean) decrease while volatility (standard deviation) increase during the crisis period compared with the pre-crisis period. Inspection of the third and fourth moments of each returns suggests a change in the returns distributions from negative skewness in the pre-crisis period to either smaller negative skewness or positive skewness in the crisis period in most cases. Not surprisingly, kurtosis rises during the crisis period.

Table 5 reports the co-moment statistics of the equity returns between the US and the 43 selected markets during pre-crisis and crisis periods. As expected, the correlation between the US and the selected market (except for Colombia) increases during the crisis period, indicating that equity returns between markets are strongly correlated in the crisis period. Both forms of co-skewness, which measures the relationship between expected returns and volatility, switch from left- to right-skewed in most cases during the crisis period. Co-volatility, which measures the correlation between volatilities, increases during the crisis period. The higher value of co-volatility in the crisis period implies that return volatility is high in both markets, thus increasing contagion risk in the crisis period.

\subsection{Contagion channels during the four financial crises}

Tables 6, 7, 8, and 9 present the empirical results of single- and multiple-channel tests of contagion during the four financial crises of 2007-2021 (the subprime mortgage crisis, the Great Recession crisis, the European debt crisis and the COVID pandemic). Under the null hypothesis of no contagion, the single-channel test statistics for the $S T_{1: 1}, S T_{1: 2}, S T_{2: 1}$ and $S T_{2: 2}$ are distributed asymptotically as $\chi_{1}^{2}$ where the $5 \%$ critical value is 3.84 , and the multiple-channel test statistic for the $M T$ is distributed asymptotically as $\chi_{4}^{2}$ where the $5 \%$ critical value is 9.49 .

\subsubsection{Contagion from the USA during the subprime mortgage crisis}

Table 6 presents the single- and multiple-channel tests of contagion based on changes in correlation, co-skewness and co-volatility during the subprime mortgage crisis with the source country specified to be the USA. Inspection of Table 6 reveals that among the

Footnote 8 continued

cross market relationships that always exist) and address any serial correlation. The VAR model is given by

$$
R_{t}=\phi(L) R_{t}+u_{t}
$$

where $R_{t}=\left[x_{t}, y_{t}\right]^{\prime}$ is a transposed vector of returns across a set of equity markets during the non-crisis $\left(x_{t}\right)$ and crisis $\left(y_{t}\right)$ periods; $\phi(L)$ is a vector of lags, and $u_{t}$ is a vector of the residual terms. In order to deal with equity markets open in different time zones, two-day rolling average returns are used in the VAR model. The residuals $u_{t}$ are treated as financial shocks and are used in the calculation of the correlation contagion statistic in (8), the co-skewness contagion statistics in (10) and (11), the co-volatility contagion statistic in (14), and the multiple-channel test of contagion statistic in (17). To conduct the contagion tests during the three episodes of financial crises from 2007 to 2013, the VAR model with 5 lags is estimated based on the sample period of 2005 to 2013. As for testing contagion during the COVID pandemic, a VAR model with 5 lags is estimated based on the sample period of 2019 to 2021. 
Table 4 Descriptive statistics of equity returns for 44 countries in four regions during pre-crisis (PC) and crisis (C) periods

\begin{tabular}{|c|c|c|c|c|c|c|c|c|c|}
\hline \multirow[t]{2}{*}{ Region } & \multirow[t]{2}{*}{ Country } & \multicolumn{2}{|c|}{ Mean } & \multicolumn{2}{|l|}{$\mathrm{SD}$} & \multicolumn{2}{|c|}{ Skewness } & \multicolumn{2}{|c|}{ Kurtosis } \\
\hline & & $\mathrm{PC}$ & $\mathrm{C}$ & $\mathrm{PC}$ & $\mathrm{C}$ & $\mathrm{PC}$ & $\mathrm{C}$ & $\mathrm{PC}$ & $\mathrm{C}$ \\
\hline Africa & S. Africa & 0.09 & 0.04 & 1.56 & 3.25 & -0.56 & -0.21 & 5.73 & 5.43 \\
\hline \multirow[t]{8}{*}{ Americas } & Argentina & 0.06 & 0.04 & 1.48 & 2.95 & -0.39 & -0.63 & 5.13 & 5.92 \\
\hline & Brazil & 0.16 & 0.06 & 1.85 & 4.04 & -0.52 & -0.28 & 4.38 & 7.33 \\
\hline & Canada & 0.09 & -0.02 & 0.93 & 3.00 & -0.42 & -0.57 & 3.83 & 5.67 \\
\hline & Chile & 0.09 & 0.08 & 0.76 & 1.61 & -0.67 & -0.90 & 5.81 & 7.22 \\
\hline & Colombia & 0.17 & 0.06 & 1.88 & 1.88 & -0.52 & -0.36 & 13.96 & 5.96 \\
\hline & Mexico & 0.13 & 0.00 & 1.39 & 3.03 & -0.19 & 0.10 & 5.85 & 6.18 \\
\hline & Peru & 0.20 & 0.09 & 1.59 & 3.50 & -0.46 & -0.16 & 4.61 & 5.49 \\
\hline & USA & 0.04 & -0.03 & 0.63 & 2.25 & -0.33 & 0.11 & 4.72 & 6.87 \\
\hline \multirow[t]{13}{*}{ Asia } & Australia & 0.09 & 0.03 & 0.98 & 3.05 & -0.48 & -0.96 & 4.17 & 7.20 \\
\hline & China & 0.20 & 0.13 & 1.60 & 2.15 & -0.66 & -0.10 & 7.66 & 4.81 \\
\hline & Hong Kong & 0.07 & 0.04 & 0.87 & 2.81 & -0.43 & 0.16 & 4.60 & 7.14 \\
\hline & India & 0.12 & 0.07 & 1.41 & 2.75 & -0.85 & 0.35 & 7.02 & 8.96 \\
\hline & Indonesia & 0.13 & 0.10 & 1.54 & 2.55 & -1.28 & -0.42 & 14.94 & 6.74 \\
\hline & Japan & 0.04 & 0.00 & 1.12 & 2.42 & -0.20 & -0.19 & 4.20 & 6.83 \\
\hline & Korea & 0.14 & 0.02 & 1.20 & 3.49 & -0.41 & 0.13 & 4.04 & 11.45 \\
\hline & Malaysia & 0.08 & 0.06 & 0.72 & 1.24 & -0.82 & 0.16 & 9.25 & 4.59 \\
\hline & New Zealand & 0.04 & 0.00 & 0.97 & 2.49 & -0.31 & -0.45 & 3.47 & 5.09 \\
\hline & Philippines & 0.13 & 0.05 & 1.35 & 2.09 & -0.59 & -1.09 & 6.76 & 10.22 \\
\hline & Singapore & 0.10 & 0.04 & 0.94 & 2.42 & -0.67 & -0.13 & 5.84 & 5.09 \\
\hline & Taiwan & 0.06 & 0.08 & 1.00 & 2.03 & -0.57 & -0.10 & 5.32 & 4.86 \\
\hline & Thailand & 0.06 & 0.05 & 1.38 & 2.12 & -2.19 & -0.93 & 36.13 & 7.95 \\
\hline \multirow[t]{14}{*}{ Europe } & Austria & 0.09 & -0.15 & 1.06 & 3.80 & -0.57 & -0.01 & 6.41 & 4.38 \\
\hline & Belgium & 0.06 & -0.06 & 0.88 & 2.58 & -0.23 & -0.20 & 4.57 & 5.23 \\
\hline & Bulgaria & 0.14 & -0.24 & 1.08 & 2.70 & 0.05 & -0.76 & 5.50 & 5.61 \\
\hline & Denmark & 0.10 & -0.05 & 0.91 & 2.52 & -0.84 & -0.29 & 6.23 & 6.30 \\
\hline & Finland & 0.09 & -0.05 & 1.03 & 2.72 & -0.13 & 0.04 & 5.34 & 4.53 \\
\hline & France & 0.06 & -0.02 & 0.92 & 2.89 & -0.23 & 0.18 & 4.20 & 6.36 \\
\hline & Germany & 0.11 & -0.02 & 1.06 & 2.93 & -0.56 & 0.03 & 6.23 & 4.93 \\
\hline & Greece & 0.09 & -0.10 & 1.10 & 2.90 & -0.37 & -0.20 & 5.82 & 4.86 \\
\hline & Hungary & 0.10 & -0.01 & 1.65 & 3.95 & -0.26 & -0.02 & 4.20 & 6.23 \\
\hline & Ireland & 0.05 & -0.11 & 0.99 & 3.01 & -0.65 & -0.68 & 7.16 & 6.11 \\
\hline & Italy & 0.04 & -0.06 & 0.87 & 2.98 & -0.28 & 0.09 & 3.90 & 5.38 \\
\hline & Netherlands & 0.07 & -0.05 & 0.86 & 3.01 & -0.17 & -0.02 & 4.76 & 6.13 \\
\hline & Norway & 0.11 & -0.03 & 1.47 & 4.08 & -0.49 & -0.27 & 5.86 & 4.56 \\
\hline & Poland & 0.11 & -0.07 & 1.68 & 3.65 & -0.17 & -0.07 & 3.80 & 4.40 \\
\hline
\end{tabular}


Table 4 continued

\begin{tabular}{|c|c|c|c|c|c|c|c|c|c|}
\hline \multirow[t]{2}{*}{ Region } & \multirow[t]{2}{*}{ Country } & \multicolumn{2}{|c|}{ Mean } & \multicolumn{2}{|l|}{ SD } & \multicolumn{2}{|c|}{ Skewness } & \multicolumn{2}{|c|}{ Kurtosis } \\
\hline & & $\mathrm{PC}$ & $\mathrm{C}$ & $\mathrm{PC}$ & $\mathrm{C}$ & $\mathrm{PC}$ & C & PC & $\mathrm{C}$ \\
\hline & Portugal & 0.08 & 0.01 & 0.76 & 2.30 & 0.34 & -0.05 & 5.43 & 8.77 \\
\hline & Romania & 0.16 & -0.06 & 1.79 & 3.50 & -0.46 & -0.37 & 8.82 & 4.71 \\
\hline & Russia & 0.18 & 0.02 & 1.60 & 4.09 & -0.96 & -0.22 & 8.71 & 7.84 \\
\hline & Spain & 0.08 & 0.02 & 0.89 & 2.76 & -0.19 & 0.03 & 4.16 & 6.15 \\
\hline & Sweden & 0.09 & 0.01 & 1.11 & 2.99 & -0.32 & -0.09 & 7.39 & 4.24 \\
\hline & Switzerland & 0.06 & 0.00 & 0.83 & 2.19 & -0.32 & 0.21 & 4.48 & 5.74 \\
\hline & Turkey & 0.11 & 0.04 & 2.29 & 3.34 & -0.67 & -0.06 & 5.77 & 6.83 \\
\hline & UK & 0.06 & -0.03 & 0.81 & 2.78 & -0.16 & 0.00 & 4.15 & 6.67 \\
\hline
\end{tabular}

The pre-crisis period is from January 1, 2005, to July 25, 2007, and the crisis period is from September 15 , 2008, to December 31, 2009

Table 5 Co-moment statistics of equity returns for 43 equity markets with the US equity market during pre-crisis $(\mathrm{PC})$ and crisis $(\mathrm{C})$ periods

\begin{tabular}{|c|c|c|c|c|c|c|c|c|c|}
\hline \multirow[t]{2}{*}{ Region } & \multirow[t]{2}{*}{ Country $(j)$} & \multicolumn{2}{|c|}{ Correlation } & \multicolumn{2}{|c|}{ Co-skewness ${ }_{1}^{2}$} & \multicolumn{2}{|c|}{ Co-skewness ${ }_{2}^{1}$} & \multicolumn{2}{|c|}{ Co-volatility } \\
\hline & & $\mathrm{PC}$ & $\mathrm{C}$ & $\mathrm{PC}$ & $\mathrm{C}$ & $\mathrm{PC}$ & $\mathrm{C}$ & $\mathrm{PC}$ & $\mathrm{C}$ \\
\hline Africa & S. Africa & 0.25 & 0.42 & -0.14 & -0.30 & -0.10 & -0.25 & 1.50 & 2.75 \\
\hline \multirow[t]{8}{*}{ Americas } & Argentina & 0.47 & 0.62 & -0.35 & -0.59 & -0.31 & -0.47 & 2.99 & 3.34 \\
\hline & Brazil & 0.52 & 0.72 & -0.27 & -0.07 & -0.21 & -0.02 & 2.58 & 5.30 \\
\hline & Canada & 0.46 & 0.72 & -0.15 & -0.53 & -0.18 & -0.32 & 2.09 & 3.50 \\
\hline & Chile & 0.33 & 0.42 & -0.26 & -0.49 & -0.28 & -0.34 & 2.66 & 3.39 \\
\hline & Colombia & 0.26 & 0.26 & -0.01 & -0.21 & -0.02 & -0.52 & 2.23 & 2.27 \\
\hline & Mexico & 0.58 & 0.72 & -0.15 & 0.13 & -0.23 & 0.08 & 3.14 & 4.89 \\
\hline & Peru & 0.33 & 0.65 & -0.17 & -0.29 & -0.26 & -0.20 & 1.90 & 3.80 \\
\hline & USA & 1.00 & 1.00 & -0.33 & 0.11 & -0.33 & 0.11 & 4.72 & 6.87 \\
\hline \multirow[t]{13}{*}{ Asia } & Australia & 0.04 & 0.26 & 0.00 & -0.11 & -0.12 & -0.07 & 0.98 & 2.31 \\
\hline & China & 0.08 & 0.13 & -0.29 & 0.05 & -0.32 & 0.24 & 2.34 & 1.41 \\
\hline & Hong Kong & 0.11 & 0.36 & -0.03 & 0.39 & -0.09 & 0.38 & 1.05 & 3.74 \\
\hline & India & 0.09 & 0.42 & -0.02 & -0.02 & -0.01 & -0.03 & 1.28 & 2.18 \\
\hline & Indonesia & -0.03 & 0.15 & 0.09 & -0.11 & -0.09 & -0.43 & 1.11 & 1.80 \\
\hline & Japan & 0.05 & 0.01 & -0.08 & 0.10 & -0.01 & -0.14 & 0.89 & 1.62 \\
\hline & Korea & 0.09 & 0.31 & -0.10 & 0.37 & -0.12 & 0.07 & 1.09 & 3.22 \\
\hline & Malaysia & 0.04 & 0.21 & -0.12 & 0.06 & -0.25 & -0.38 & 1.60 & 2.04 \\
\hline & New Zealand & -0.06 & 0.20 & -0.02 & -0.27 & -0.13 & -0.42 & 0.98 & 1.63 \\
\hline & Philippines & 0.01 & 0.07 & 0.02 & -0.11 & -0.08 & -0.25 & 0.92 & 1.35 \\
\hline & Singapore & 0.07 & 0.39 & 0.04 & 0.01 & -0.11 & 0.10 & 1.13 & 2.74 \\
\hline & Taiwan & 0.04 & 0.16 & -0.11 & 0.05 & -0.09 & -0.26 & 0.93 & 1.45 \\
\hline & Thailand & 0.04 & 0.36 & 0.02 & -0.32 & -0.10 & -0.11 & 0.68 & 1.87 \\
\hline
\end{tabular}


Table 5 continued

\begin{tabular}{|c|c|c|c|c|c|c|c|c|c|}
\hline \multirow[t]{2}{*}{ Region } & \multirow[t]{2}{*}{ Country $(j)$} & \multicolumn{2}{|c|}{ Correlation } & \multicolumn{2}{|c|}{ Co-skewness ${ }_{1}^{2}$} & \multicolumn{2}{|c|}{ Co-skewness ${ }_{2}^{1}$} & \multicolumn{2}{|c|}{ Co-volatility } \\
\hline & & $\mathrm{PC}$ & $\mathrm{C}$ & $\mathrm{PC}$ & $\mathrm{C}$ & $\mathrm{PC}$ & $\mathrm{C}$ & PC & $\mathrm{C}$ \\
\hline \multirow[t]{22}{*}{ Europe } & Austria & 0.24 & 0.45 & -0.20 & -0.06 & -0.21 & -0.23 & 1.47 & 2.80 \\
\hline & Belgium & 0.34 & 0.54 & -0.13 & -0.16 & -0.17 & -0.27 & 1.84 & 3.41 \\
\hline & Bulgaria & -0.04 & 0.15 & 0.01 & -0.22 & 0.06 & -0.14 & 1.00 & 1.88 \\
\hline & Denmark & 0.25 & 0.46 & -0.17 & -0.24 & -0.17 & -0.21 & 1.55 & 2.86 \\
\hline & Finland & 0.34 & 0.50 & -0.12 & -0.12 & -0.12 & -0.29 & 1.86 & 2.68 \\
\hline & France & 0.41 & 0.56 & -0.09 & 0.00 & -0.14 & -0.14 & 1.91 & 3.31 \\
\hline & Germany & 0.35 & 0.55 & -0.11 & -0.06 & -0.20 & -0.16 & 2.23 & 3.15 \\
\hline & Greece & 0.18 & 0.38 & -0.12 & -0.24 & -0.18 & -0.22 & 1.64 & 2.05 \\
\hline & Hungary & 0.14 & 0.46 & -0.15 & -0.25 & -0.11 & -0.22 & 1.25 & 3.18 \\
\hline & Ireland & 0.26 & 0.45 & -0.11 & -0.50 & -0.15 & -0.43 & 1.73 & 2.48 \\
\hline & Italy & 0.38 & 0.52 & -0.13 & 0.03 & -0.17 & -0.17 & 1.77 & 3.10 \\
\hline & Netherlands & 0.39 & 0.58 & -0.05 & -0.14 & -0.11 & -0.25 & 1.75 & 3.42 \\
\hline & Norway & 0.21 & 0.50 & -0.05 & -0.23 & -0.05 & -0.27 & 1.33 & 2.64 \\
\hline & Poland & 0.20 & 0.41 & -0.17 & -0.14 & -0.12 & -0.15 & 1.30 & 2.07 \\
\hline & Portugal & 0.16 & 0.43 & -0.11 & -0.03 & -0.12 & -0.08 & 1.13 & 3.13 \\
\hline & Romania & 0.01 & 0.38 & 0.03 & -0.13 & 0.07 & -0.04 & 0.97 & 1.88 \\
\hline & Russia & 0.16 & 0.32 & -0.14 & -0.26 & -0.05 & -0.24 & 1.33 & 2.36 \\
\hline & Spain & 0.40 & 0.55 & -0.11 & -0.13 & -0.16 & -0.18 & 1.76 & 3.19 \\
\hline & Sweden & 0.30 & 0.49 & -0.16 & -0.15 & -0.19 & -0.23 & 1.88 & 2.89 \\
\hline & Switzerland & 0.30 & 0.50 & -0.10 & -0.06 & -0.13 & -0.23 & 1.81 & 3.58 \\
\hline & Turkey & 0.21 & 0.48 & -0.18 & 0.01 & -0.15 & -0.12 & 1.41 & 2.75 \\
\hline & UK & 0.36 & 0.55 & -0.02 & -0.16 & -0.12 & -0.22 & 1.69 & 3.52 \\
\hline
\end{tabular}

The co-moment statistics of equity returns between the USA $(i)$ and selected market $(j)$ include correlation $\left(r_{i t}^{1}, r_{j t}^{1}\right)$, co-skewness $12\left(r_{i t}^{1}, r_{j t}^{2}\right)$, co-skewness $21\left(r_{i t}^{2}, r_{j t}^{1}\right)$ and co-volatility $\left(r_{i t}^{2}, r_{j t}^{2}\right)$, which are computed as $T^{-1} \sum_{t=1}^{T} z_{i, t}^{a} z_{j, t}^{b}$, where $z_{i, t}=\left(r_{i t}-\widehat{\mu}_{i}\right) / \widehat{\sigma}_{i}$ and $z_{j, t}=\left(r_{j t}-\widehat{\mu}_{j}\right) / \widehat{\sigma}_{j}$

four regions, the Americas region is the most affected by the subprime mortgage crisis, followed by the Asian and European regions, with the African region the least affected by the crisis based on single- and multiple-channel tests. In particular, all countries especially those located in the Americas region are more exposed to contagion risk through either single channel or multiple channel of correlation, co-skewness and covolatility. In terms of single channel tests, the correlation channel ( $\left.S T_{1: 1}\right)$ seems to be the most dominant in detecting contagion from the equity returns of the USA to the equity returns of the other North and South American equity markets, followed by the co-volatility channel $\left(S T_{2: 2}\right)$, where the contagion effect is detected from the square returns of the US equity markets to squared returns of the other North and South American equity markets. Compared with correlation and co-volatility, co-skewness channels ( $S T_{1: 2}$ and $S T_{2: 1}$ ) are weaker in detecting contagion between the returns of the US equity market and the squared returns of the other North and South American equity markets. In terms of multiple channel test, all joint co-moments of correlation, 
co-skewness and co-volatility $(M T)$ are affected by contagion from the US equity market to the other North and South American equity markets during the subprime mortgage crisis.

\subsubsection{Contagion from the US during the Great Recession crisis}

Table 7 presents the empirical results of the single- and multiple-channel tests of contagion during the Great Recession crisis of 2008-2009, with the source market is again specified to be the USA. The results show that contagion effects are widespread from the US equity market to the selected equity markets in four regions including Africa, Americas, Asia and Europe during the Great Recession. Among these regions, the European regions are most affected by the crisis from the US equity market since all equity markets in the European region experienced a dramatic change in joint correlation, co-skewness and co-volatility with the US equity market in the crisis period compared with the non-crisis period. This result also anticipates the fact that after the end of the Great Recession, the European region faced its own financial crisis, namely the European sovereign debt crisis due to the problem of refinancing government debt (Fry-McKibbin and Hsiao 2018). Besides Europe, the African, Asian and Americas regions are also exposed to contagion risk during the Great Recession as evident by financial market contagion between the US and selected equity markets through either single channel or multiplier channel of correlation, co-skewness and co-volatility.

\subsubsection{Contagion from Greece during the European debt crisis}

Table 8 presents the empirical results of the single- and multiple-channel tests of contagion during the European debt crisis of 2010-2013, with the source market specified to be Greece. Table 8 reveals significant evidence of contagion from Greece to selected equity markets in four regions through either single or multiple-channel of correlation, co-skewness and co-volatility during the European debt crisis. Not surprisingly, among the four regions, the European region is the most affected region by the crisis, with all equity markets except for Bulgaria affected by the crisis in at least two transmission channels. The African, Americas and Asian regions are also affected by the European debt crisis, but the contagion effect is not so strong as for the European region.

\subsubsection{Contagion from China during the COVID pandemic}

Table 9 presents the empirical results of contagion tests during the COVID pandemic of 2019-2021, with the source market specified to be China. Table 9 shows significant evidence of contagion from China's equity market to selected markets in the Americas and Asian and European regions during the COVID pandemic through the single channels of correlation, co-skewness or co-volatility. Among the four regions, the Asian region is the most affected by contagion from China, followed by the Americas, with no contagion from China to the African region during the COVID pandemic. 
Table 6 Contagion from the US equity market to recipient markets $(j)$ during the subprime mortgage crisis of 2007-2008

\begin{tabular}{|c|c|c|c|c|c|c|}
\hline \multirow[t]{2}{*}{ Region } & \multirow[t]{2}{*}{ Recipient $(j)$} & \multicolumn{5}{|c|}{ Contagion tests } \\
\hline & & $S T_{1: 1}$ & $S T_{1: 2}$ & $S T_{2: 1}$ & $S T_{2: 2}$ & $M T$ \\
\hline Africa & S. Africa & $5.92^{*}$ & 3.02 & 0.91 & 0.75 & 4.10 \\
\hline \multirow[t]{7}{*}{ Americas } & Argentina & $15.35^{*}$ & 1.79 & 0.99 & $8.79^{*}$ & $38.59^{*}$ \\
\hline & Brazil & $32.35^{*}$ & 0.14 & 0.62 & 1.39 & $30.79 *$ \\
\hline & Canada & $20.79^{*}$ & 2.09 & 1.63 & 0.43 & $13.88^{*}$ \\
\hline & Chile & $8.90^{*}$ & $7.82^{*}$ & 0.92 & 0.07 & $14.79^{*}$ \\
\hline & Colombia & $5.75^{*}$ & $4.77^{*}$ & 3.59 & 1.49 & $15.68^{*}$ \\
\hline & Mexico & $12.08^{*}$ & 0.54 & 1.29 & 0.49 & $14.47^{*}$ \\
\hline & Peru & $14.14^{*}$ & 0.69 & 0.41 & $4.31^{*}$ & $22.67^{*}$ \\
\hline \multirow[t]{13}{*}{ Asia } & Australia & 0.80 & 0.75 & 2.61 & 0.52 & 4.21 \\
\hline & China & 3.45 & $5.10^{*}$ & 0.00 & $26.48^{*}$ & $33.45^{*}$ \\
\hline & Hong Kong & $4.84^{*}$ & 0.00 & 0.06 & 0.05 & 2.57 \\
\hline & India & 3.31 & 1.32 & 0.05 & 0.05 & 3.13 \\
\hline & Indonesia & 1.60 & 0.13 & 0.01 & 0.87 & 1.17 \\
\hline & Japan & 0.28 & 0.37 & $4.22^{*}$ & 1.68 & 6.39 \\
\hline & Korea & 0.65 & $4.42^{*}$ & 0.05 & 1.15 & 5.85 \\
\hline & Malaysia & 3.77 & 1.30 & 1.62 & $21.10^{*}$ & $28.45^{*}$ \\
\hline & New Zealand & 1.26 & 0.04 & $4.16^{*}$ & 2.33 & 7.56 \\
\hline & Philippines & 0.11 & 0.44 & 0.00 & $6.29 *$ & 7.05 \\
\hline & Singapore & $4.05^{*}$ & 1.11 & 0.57 & 0.24 & 3.80 \\
\hline & Taiwan & 0.31 & $6.37^{*}$ & 0.89 & $13.26^{*}$ & $21.50^{*}$ \\
\hline & Thailand & 0.00 & 0.06 & 0.75 & $11.40^{*}$ & $12.56^{*}$ \\
\hline \multirow[t]{14}{*}{ Europe } & Austria & 0.80 & 0.75 & 2.61 & 0.52 & 7.67 \\
\hline & Belgium & $5.41^{*}$ & 0.40 & 0.00 & 0.98 & 2.16 \\
\hline & Bulgaria & 0.50 & 3.65 & $4.40^{*}$ & 1.09 & 9.37 \\
\hline & Denmark & $5.28^{*}$ & 0.02 & 0.55 & 0.43 & 3.03 \\
\hline & Finland & $26.43^{*}$ & 1.32 & 0.19 & 0.08 & $15.50^{*}$ \\
\hline & France & $17.09^{*}$ & 0.24 & 0.52 & 1.82 & 7.11 \\
\hline & Germany & $17.92 *$ & 0.00 & 0.02 & 0.13 & $12.17^{*}$ \\
\hline & Greece & 2.92 & 0.05 & 0.01 & $5.32^{*}$ & 5.46 \\
\hline & Hungary & 0.08 & $6.38^{*}$ & 1.97 & 0.72 & $9.87^{*}$ \\
\hline & Ireland & 0.14 & $4.85^{*}$ & 2.71 & $4.52^{*}$ & $14.43^{*}$ \\
\hline & Italy & $14.23^{*}$ & 0.12 & 0.09 & 1.38 & 5.82 \\
\hline & Netherlands & $19.62^{*}$ & 1.27 & 1.28 & 0.88 & $11.18^{*}$ \\
\hline & Norway & $13.94^{*}$ & 0.32 & 1.42 & 0.42 & 8.64 \\
\hline & Poland & 0.50 & 0.08 & 0.26 & 1.02 & 1.39 \\
\hline
\end{tabular}


Table 6 continued

\begin{tabular}{lllllll}
\hline Region & Recipient $(j)$ & \multicolumn{5}{l}{ Contagion tests } \\
\cline { 3 - 6 } & $S T_{1: 1}$ & $S T_{1: 2}$ & $S T_{2: 1}$ & $S T_{2: 2}$ & $M T$ \\
\hline Portugal & $4.30^{*}$ & 0.20 & 0.34 & 1.89 & 3.50 \\
Romania & 0.06 & 0.18 & 0.62 & $5.67^{*}$ & 6.68 \\
Russia & $6.52^{*}$ & 2.06 & 0.00 & $7.04^{*}$ & $10.04^{*}$ \\
Spain & $18.86^{*}$ & 0.48 & 0.04 & 2.26 & 7.72 \\
Sweden & $8.45^{*}$ & 0.10 & 1.42 & 1.25 & 5.17 \\
Switzerland & $7.72^{*}$ & 0.09 & 0.39 & 0.15 & 4.26 \\
Turkey & 2.23 & 2.97 & 0.06 & $6.05^{*}$ & 9.32 \\
UK & $17.75^{*}$ & 0.01 & 0.02 & 0.98 & 7.05 \\
\hline
\end{tabular}

$S T_{1: 1}$ is the correlation contagion test in (8), $S T_{1: 2}$ and $S T_{2: 1}$ are the co-skewness contagion tests in (10) and (11), $S T_{2: 2}$ is the co-volatility contagion test in (14), $M T$ is the joint test of correlation, co-skewness and co-volatility in (17). * denotes the significance of contagion at the $5 \%$ level

Table 7 Contagion from the US equity market to recipient markets $(j)$ during the Great Recession of 2008-2009

\begin{tabular}{|c|c|c|c|c|c|c|}
\hline \multirow[t]{2}{*}{ Region } & \multirow[t]{2}{*}{ Recipient $(j)$} & \multicolumn{5}{|c|}{ Contagion tests } \\
\hline & & $S T_{1: 1}$ & $S T_{1: 2}$ & $S T_{2: 1}$ & $S T_{2: 2}$ & $M T$ \\
\hline Africa & S. Africa & 0.22 & $4.36^{*}$ & 2.82 & $50.38^{*}$ & $73.98^{*}$ \\
\hline \multirow[t]{7}{*}{ Americas } & Argentina & $7.44^{*}$ & 0.03 & 1.63 & $23.53^{*}$ & $29.42^{*}$ \\
\hline & Brazil & $12.95^{*}$ & 0.97 & 1.58 & $46.75^{*}$ & $68.80^{*}$ \\
\hline & Canada & 3.16 & $11.51^{*}$ & $6.40^{*}$ & $47.21^{*}$ & $101.89^{*}$ \\
\hline & Chile & $7.91^{*}$ & 0.85 & $5.44^{*}$ & $18.09^{*}$ & $25.90^{*}$ \\
\hline & Colombia & $9.16^{*}$ & 1.50 & 0.02 & 0.24 & 6.91 \\
\hline & Mexico & $25.85^{*}$ & 0.02 & 0.00 & $14.03^{*}$ & $14.27^{*}$ \\
\hline & Peru & 0.84 & 1.00 & 0.46 & $41.79^{*}$ & $62.12^{*}$ \\
\hline \multirow[t]{13}{*}{ Asia } & Australia & 1.96 & 3.66 & 2.76 & $41.50^{*}$ & $62.00^{*}$ \\
\hline & China & 0.47 & 2.27 & $13.58^{*}$ & $10.97^{*}$ & $26.97^{*}$ \\
\hline & Hong Kong & 0.09 & 0.52 & 3.25 & $27.79^{*}$ & $36.99^{*}$ \\
\hline & India & 0.32 & 2.49 & 0.77 & $12.74^{*}$ & $19.34^{*}$ \\
\hline & Indonesia & $4.37^{*}$ & 0.80 & 3.60 & 2.90 & $10.16^{*}$ \\
\hline & Japan & 0.21 & 0.45 & 0.25 & 0.56 & 1.42 \\
\hline & Korea & 0.05 & 1.12 & 0.00 & $12.30^{*}$ & $15.01^{*}$ \\
\hline & Malaysia & 0.07 & $8.74^{*}$ & 1.15 & 0.88 & $11.30^{*}$ \\
\hline & New Zealand & $12.95^{*}$ & $4.53^{*}$ & $10.79^{*}$ & $20.19^{*}$ & $48.93^{*}$ \\
\hline & Philippines & 0.97 & $4.87^{*}$ & 0.00 & $5.41^{*}$ & $11.64^{*}$ \\
\hline & Singapore & 0.66 & 0.06 & 0.00 & $23.62^{*}$ & $31.35^{*}$ \\
\hline & Taiwan & 0.57 & 1.98 & 0.77 & $3.93^{*}$ & 7.36 \\
\hline & Thailand & $8.51^{*}$ & 2.21 & $5.67^{*}$ & $42.15^{*}$ & $67.69^{*}$ \\
\hline
\end{tabular}


Table 7 continued

\begin{tabular}{|c|c|c|c|c|c|c|}
\hline \multirow[t]{2}{*}{ Region } & \multirow[t]{2}{*}{ Recipient $(j)$} & \multicolumn{5}{|c|}{ Contagion tests } \\
\hline & & $S T_{1: 1}$ & $S T_{1: 2}$ & $S T_{2: 1}$ & $S T_{2: 2}$ & $M T$ \\
\hline \multirow[t]{22}{*}{ Europe } & Austria & 1.96 & 3.66 & 2.76 & $41.50^{*}$ & $70.96^{*}$ \\
\hline & Belgium & $6.42^{*}$ & $9.13^{*}$ & 3.81 & $79.50^{*}$ & $118.22^{*}$ \\
\hline & Bulgaria & $11.11^{*}$ & 2.06 & 3.38 & $7.98^{*}$ & $19.90^{*}$ \\
\hline & Denmark & 1.07 & $6.00^{*}$ & $8.72 *$ & $34.22^{*}$ & $58.89^{*}$ \\
\hline & Finland & $13.29^{*}$ & 1.25 & $4.69^{*}$ & $48.62^{*}$ & $62.24^{*}$ \\
\hline & France & $12.98^{*}$ & 3.83 & 3.80 & $46.38^{*}$ & $66.40^{*}$ \\
\hline & Germany & $6.07^{*}$ & 2.89 & $4.01^{*}$ & $32.10^{*}$ & $47.65^{*}$ \\
\hline & Greece & 0.32 & 2.30 & 2.09 & $38.57^{*}$ & $48.96^{*}$ \\
\hline & Hungary & 0.17 & 1.78 & 2.98 & $16.53^{*}$ & $26.82^{*}$ \\
\hline & Ireland & 1.41 & $8.74^{*}$ & $5.03^{*}$ & $96.11^{*}$ & $134.10^{*}$ \\
\hline & Italy & $8.87^{*}$ & 2.97 & 2.98 & $55.48^{*}$ & $75.17^{*}$ \\
\hline & Netherlands & $8.25^{*}$ & $15.41^{*}$ & $7.64^{*}$ & $82.02^{*}$ & $143.78^{*}$ \\
\hline & Norway & 0.25 & $8.66^{*}$ & $6.82^{*}$ & $59.17^{*}$ & $92.58^{*}$ \\
\hline & Poland & 0.00 & 2.26 & 2.61 & $33.77^{*}$ & $47.28^{*}$ \\
\hline & Portugal & 0.48 & $5.11^{*}$ & $6.20^{*}$ & $72.98^{*}$ & $110.61^{*}$ \\
\hline & Romania & $10.03^{*}$ & 1.45 & 3.36 & $11.01^{*}$ & $25.74^{*}$ \\
\hline & Russia & 1.45 & $5.39^{*}$ & 3.39 & $60.22^{*}$ & $75.50^{*}$ \\
\hline & Spain & $7.97^{*}$ & $5.49^{*}$ & 3.47 & $49.64^{*}$ & $75.57^{*}$ \\
\hline & Sweden & $10.38^{*}$ & $8.28^{*}$ & 2.87 & $43.67^{*}$ & $63.19^{*}$ \\
\hline & Switzerland & $4.98^{*}$ & $9.66^{*}$ & $7.13^{*}$ & $62.73^{*}$ & $96.18^{*}$ \\
\hline & Turkey & 0.00 & 0.87 & 0.84 & $58.40^{*}$ & $78.24^{*}$ \\
\hline & UK & $10.29 *$ & $12.04^{*}$ & $6.25^{*}$ & $68.71^{*}$ & $114.02^{*}$ \\
\hline
\end{tabular}

$S T_{1: 1}$ is the correlation contagion test in (8), $S T_{1: 2}$ and $S T_{2: 1}$ are the co-skewness contagion tests in (10) and (11), $S T_{2: 2}$ is the co-volatility contagion test in (14), $M T$ is the joint test of correlation, co-skewness and co-volatility in (17). * denotes the significance of contagion at the $5 \%$ level

The results for the multiple channel test reveal that contagion effects are widespread from China's equity market to the Americas' equity markets (Argentina, Colombia and Peru), Asian equity markets (Australia, Hong Kong, Korea, Singapore, Taiwan and Thailand) and European equity markets (Bulgaria, Greece and Ireland) through joint channels of correlation, co-skewness and co-volatility.

Overall, the results indicate that among the four episodes of crises from 2007 to 2021, the Great Recession seems to be the most pervasive crisis in leading to contagion between the US equity market and the selected equity markets in four regions, followed by the European debt crisis and the COVID pandemic, with the subprime mortgage crisis being the least pervasive. When considering which single channel of contagion is most important, the co-volatility channel is the most dominant, followed by the correlation channel, with the co-skewness channels the least important in the financial market contagion. The results are consistent with the fact that co-volatility, one of the tail dependence, can better detect contagion than the correlation and co-skewness 
Table 8 Contagion from the Greek equity market to recipient markets $(j)$ during the European debt crisis of 2010-2013

\begin{tabular}{|c|c|c|c|c|c|c|}
\hline \multirow[t]{2}{*}{ Region } & \multirow[t]{2}{*}{ Recipient $(j)$} & \multicolumn{5}{|c|}{ Contagion tests } \\
\hline & & $S T_{1: 1}$ & $S T_{1: 2}$ & $S T_{2: 1}$ & $S T_{2: 2}$ & $M T$ \\
\hline Africa & S. Africa & $116.61^{*}$ & $4.87^{*}$ & 1.24 & $19.11^{*}$ & $49.98^{*}$ \\
\hline \multirow[t]{8}{*}{ Americas } & Argentina & $3.97^{*}$ & 3.36 & 0.01 & 1.86 & 6.89 \\
\hline & Brazil & $16.34^{*}$ & 0.00 & 0.37 & $16.40^{*}$ & $18.97^{*}$ \\
\hline & Canada & $12.77^{*}$ & 0.23 & 0.62 & $30.90^{*}$ & $33.29^{*}$ \\
\hline & Chile & $7.09^{*}$ & 1.27 & 0.41 & 0.47 & 8.25 \\
\hline & Colombia & $8.34^{*}$ & $18.83^{*}$ & 2.47 & $264.20^{*}$ & $367.04^{*}$ \\
\hline & Mexico & $9.72 *$ & 0.01 & 0.01 & 0.29 & 5.80 \\
\hline & Peru & $17.47^{*}$ & 0.56 & 0.97 & 0.22 & $12.64^{*}$ \\
\hline & USA & 2.05 & 0.13 & 0.14 & $65.08 *$ & $70.96^{*}$ \\
\hline \multirow[t]{13}{*}{ Asia } & Australia & $39.64^{*}$ & $8.35^{*}$ & 0.37 & $34.47^{*}$ & $50.19^{*}$ \\
\hline & China & 0.13 & 0.25 & 2.42 & $9.02 *$ & $12.12^{*}$ \\
\hline & Hong Kong & $16.04^{*}$ & 0.31 & 0.01 & $20.82^{*}$ & $24.26^{*}$ \\
\hline & India & $21.67^{*}$ & $4.48^{*}$ & 0.24 & 0.02 & $19.64^{*}$ \\
\hline & Indonesia & $9.91^{*}$ & $6.17^{*}$ & 0.13 & 0.01 & $13.87^{*}$ \\
\hline & Japan & $18.19^{*}$ & $16.18^{*}$ & 0.03 & $9.27^{*}$ & $33.75^{*}$ \\
\hline & Korea & $10.48^{*}$ & 0.01 & 0.14 & $56.64 *$ & $59.07^{*}$ \\
\hline & Malaysia & $8.80^{*}$ & 1.06 & 0.94 & 0.80 & 7.71 \\
\hline & New Zealand & 2.31 & $5.55^{*}$ & 0.23 & $10.80^{*}$ & $17.11^{*}$ \\
\hline & Philippines & $6.00^{*}$ & $5.22^{*}$ & 1.17 & 0.65 & $12.24^{*}$ \\
\hline & Singapore & $26.56^{*}$ & 0.47 & 0.00 & $18.61^{*}$ & $23.24^{*}$ \\
\hline & Taiwan & $8.59^{*}$ & 0.23 & 1.69 & $4.14^{*}$ & $9.53^{*}$ \\
\hline & Thailand & $6.28^{*}$ & 0.00 & 2.75 & $19.21^{*}$ & $23.15^{*}$ \\
\hline \multirow[t]{12}{*}{ Europe } & Austria & $91.75^{*}$ & 0.40 & 1.60 & $27.81^{*}$ & $40.29 *$ \\
\hline & Belgium & $98.34^{*}$ & 2.00 & 0.00 & $19.30^{*}$ & $35.42^{*}$ \\
\hline & Bulgaria & 0.37 & 3.50 & 0.75 & 2.12 & 6.68 \\
\hline & Denmark & $94.99^{*}$ & 0.01 & 0.53 & $12.24^{*}$ & $31.97^{*}$ \\
\hline & Finland & $75.56^{*}$ & 2.53 & 0.12 & $12.81^{*}$ & $30.83^{*}$ \\
\hline & France & $92.71^{*}$ & 1.00 & 0.00 & $44.31^{*}$ & $53.26^{*}$ \\
\hline & Germany & $162.11^{*}$ & 0.75 & 0.00 & $6.41^{*}$ & $49.89 *$ \\
\hline & Hungary & $23.81^{*}$ & 2.94 & 0.00 & $20.19^{*}$ & $26.13^{*}$ \\
\hline & Ireland & $93.36^{*}$ & 3.37 & 0.05 & $6.92^{*}$ & $37.18^{*}$ \\
\hline & Italy & $95.86^{*}$ & 0.36 & 0.12 & $43.17^{*}$ & $51.68 *$ \\
\hline & Netherlands & $107.97^{*}$ & 1.96 & 0.01 & $31.41^{*}$ & $45.28^{*}$ \\
\hline & Norway & $57.92^{*}$ & 0.04 & 0.06 & $7.49^{*}$ & $23.17^{*}$ \\
\hline
\end{tabular}


Table 8 continued

\begin{tabular}{llllll}
\hline Region & Recipient $(j)$ & \multicolumn{2}{l}{ Contagion tests } & & \\
\cline { 3 - 6 } & $S T_{1: 1}$ & $S T_{1: 2}$ & $S T_{2: 1}$ & $S T_{2: 2}$ & $M T$ \\
\hline Poland & $35.17^{*}$ & 1.48 & 0.29 & $19.96^{*}$ & $25.58^{*}$ \\
Portugal & $52.91^{*}$ & 0.72 & 0.01 & $121.20^{*}$ & $149.06^{*}$ \\
Romania & 0.71 & $8.24^{*}$ & 0.19 & $131.73^{*}$ & $172.59^{*}$ \\
Russia & $43.21^{*}$ & $4.12^{*}$ & 0.01 & $29.59^{*}$ & $118.98^{*}$ \\
Spain & $87.95^{*}$ & 0.20 & 0.21 & $79.16^{*}$ & $91.75^{*}$ \\
Sweden & $42.18^{*}$ & 0.00 & 0.03 & 0.49 & $22.92^{*}$ \\
Switzerland & $116.13^{*}$ & $6.59^{*}$ & 0.39 & $9.39^{*}$ & $50.35^{*}$ \\
Turkey & $50.93^{*}$ & 1.96 & 0.00 & $36.55^{*}$ & $134.89^{*}$ \\
UK & $123.76^{*}$ & $7.46^{*}$ & 0.24 & $25.61^{*}$ & $56.53^{*}$
\end{tabular}

$S T_{1: 1}$ is the correlation contagion test in (8), $S T_{1: 2}$ and $S T_{2: 1}$ are the co-skewness contagion tests in (10) and (11), $S T_{2: 2}$ is the co-volatility contagion test in (14), $M T$ is the joint test of correlation, co-skewness and co-volatility in (17). * denotes the significance of contagion at the $5 \%$ level

channels, especially when the crisis corresponds to the worst event occurring in one market given that the worst event occurred in another market (Garcia and Tsafack 2011).

\subsubsection{Network analysis using the MT test}

It is interesting to investigate not only the contagion effect spreading from the US, Greece or China to other countries, but also possible contagion effects between other countries. We plot network diagrams using the proposed multiple-channel test $(M T)$ for the four crises: (i) the subprime mortgage crisis (2007-2008), (ii) the Great Recession (2008-2009), (iii) the European debt crisis (2010-2013) and iv) the recent COVID pandemic (2019-2021), respectively. In each network, there are 44 nodes considered as the possible source of contagion, while links resemble the direction of the relationships between countries. The nodes are colored based on the strength of contagion using the joint test in equation (17). If the node is colored in dark red and is larger, it reveals that all 43 recipient countries are affected by the source node, while if the node is colored in orange and is smaller, it suggests that no country is affected by crisis.

Figure 2 reveals that among the four crises, the networks for the COVID pandemic are the most connected, as evident by more than 30 countries acting as the main nodes in the network. Perhaps surprisingly, among the 44 countries, China is not found to be an important node in spreading the shocks to the overall system; however, Bulgaria, Colombia, Canada, Ireland, Norway, Thailand and the UK appear as nodes affecting up to 40 countries in the network during the COVID pandemic. The Great Recession also displays a more interconnected system than the European debt crisis. In particular, more than 14 European countries shows the dark red node during the Great Recession, suggesting that European region has more linkages with other regions in equity markets. The results are consistent with the fact that the European region faced its own financial crisis during the period of 2010 to 2013. Similarly, among the four 
Table 9 Contagion from the China equity market to recipient markets $(j)$ during the COVID pandemic of 2019 to 2021

\begin{tabular}{|c|c|c|c|c|c|c|}
\hline \multirow[t]{2}{*}{ Region } & \multirow[t]{2}{*}{ Recipient $(j)$} & \multicolumn{5}{|c|}{ Contagion tests } \\
\hline & & $S T_{1: 1}$ & $S T_{1: 2}$ & $S T_{2: 1}$ & $S T_{2: 2}$ & $M T$ \\
\hline Africa & S. Africa & 1.02 & 0.44 & 1.46 & 1.70 & 8.36 \\
\hline \multirow[t]{8}{*}{ Americas } & Argentina & 1.50 & $4.38^{*}$ & $3.88^{*}$ & 0.05 & $10.34^{*}$ \\
\hline & Brazil & 0.40 & 0.69 & 1.13 & $4.73^{*}$ & 6.68 \\
\hline & Canada & 0.91 & $4.80^{*}$ & 1.64 & 0.29 & 9.26 \\
\hline & Chile & 0.31 & 0.09 & 0.26 & 2.01 & 4.04 \\
\hline & Colombia & 0.56 & $4.49^{*}$ & 2.61 & 1.23 & $11.21^{*}$ \\
\hline & Mexico & 0.34 & 1.32 & 0.97 & 0.96 & 3.49 \\
\hline & Peru & 0.01 & 0.02 & $4.01^{*}$ & $5.74^{*}$ & $12.78^{*}$ \\
\hline & USA & 0.98 & 0.02 & 0.93 & 0.00 & 2.28 \\
\hline \multirow[t]{12}{*}{ Asia } & Australia & 0.77 & 0.51 & $7.32 *$ & 0.92 & $12.40^{*}$ \\
\hline & Hong Kong & 3.09 & 0.14 & 0.16 & 2.12 & $14.68^{*}$ \\
\hline & India & 0.48 & 0.06 & 0.40 & 1.57 & 2.12 \\
\hline & Indonesia & 0.08 & 0.57 & 1.18 & 0.24 & 2.34 \\
\hline & Japan & 1.86 & 0.14 & 0.32 & 1.48 & 6.56 \\
\hline & Korea & $4.38^{*}$ & 0.88 & 0.07 & $5.36^{*}$ & $24.15^{*}$ \\
\hline & Malaysia & 0.49 & 0.03 & 0.02 & 1.05 & 2.96 \\
\hline & New Zealand & 0.42 & 0.25 & 1.09 & 0.49 & 2.96 \\
\hline & Philippines & 0.15 & 0.52 & 1.19 & $5.97^{*}$ & 8.05 \\
\hline & Singapore & 2.25 & 0.50 & 0.23 & $9.88^{*}$ & $30.33^{*}$ \\
\hline & Taiwan & $3.85^{*}$ & 0.17 & 0.20 & $5.20^{*}$ & $21.30^{*}$ \\
\hline & Thailand & 0.89 & 0.00 & 1.44 & $4.12^{*}$ & $10.34^{*}$ \\
\hline \multirow[t]{13}{*}{ Europe } & Austria & 0.99 & 0.93 & 0.66 & 0.64 & 4.88 \\
\hline & Belgium & 1.14 & 0.31 & 0.40 & 1.28 & 5.258 \\
\hline & Bulgaria & 0.01 & $17.42^{*}$ & $6.42^{*}$ & $5.71^{*}$ & $32.55^{*}$ \\
\hline & Denmark & 0.28 & 0.54 & 1.52 & 0.31 & 2.75 \\
\hline & Finland & 0.09 & 0.28 & 0.47 & 0.85 & 2.50 \\
\hline & France & 1.44 & 0.31 & 0.00 & 0.24 & 3.26 \\
\hline & Germany & 1.81 & 0.27 & 0.02 & 0.09 & 3.18 \\
\hline & Greece & 0.08 & 0.03 & 1.95 & $5.26^{*}$ & $9.70^{*}$ \\
\hline & Hungary & 0.10 & 0.07 & 0.01 & 0.05 & 0.19 \\
\hline & Ireland & 0.32 & $4.55^{*}$ & 0.39 & 3.44 & $11.15^{*}$ \\
\hline & Italy & 1.99 & 0.47 & 0.11 & 0.61 & 5.10 \\
\hline & Netherlands & 1.21 & 0.10 & 0.45 & 0.26 & 3.36 \\
\hline & Norway & 0.97 & 3.13 & 1.85 & 0.75 & $9.66^{*}$ \\
\hline
\end{tabular}


Table 9 continued

\begin{tabular}{lllllll}
\hline Region & Recipient $(j)$ & \multicolumn{6}{l}{ Contagion tests } & \multicolumn{3}{l}{} \\
\cline { 3 - 6 } & $S T_{1: 1}$ & $S T_{1: 2}$ & $S T_{2: 1}$ & $S T_{2: 2}$ & $M T$ \\
\hline Poland & 0.03 & 0.73 & 0.80 & 0.14 & 1.96 \\
Portugal & 0.63 & 0.51 & 0.00 & 0.00 & 1.36 \\
Romania & 0.39 & 0.71 & 0.20 & 0.01 & 1.42 \\
Russia & 0.67 & 0.26 & 0.32 & 0.60 & 1.53 \\
Spain & 1.15 & 0.04 & 0.07 & 0.80 & 3.46 \\
Sweden & 0.00 & 0.47 & 0.03 & 0.00 & 0.64 \\
Switzerland & 1.44 & 0.40 & 1.40 & 1.72 & 7.91 \\
Turkey & 1.25 & 0.02 & 1.48 & 1.77 & 3.93 \\
UK & 0.88 & 0.27 & 0.18 & 1.38 & 4.88
\end{tabular}

$S T_{1: 1}$ is the correlation contagion test in (8), $S T_{1: 2}$ and $S T_{2: 1}$ are the co-skewness contagion tests in (10) and (11), $S T_{2: 2}$ is the co-volatility contagion test in (14), $M T$ is the joint test of correlation, co-skewness and co-volatility in (17). * denotes the significance of contagion at the $5 \%$ level
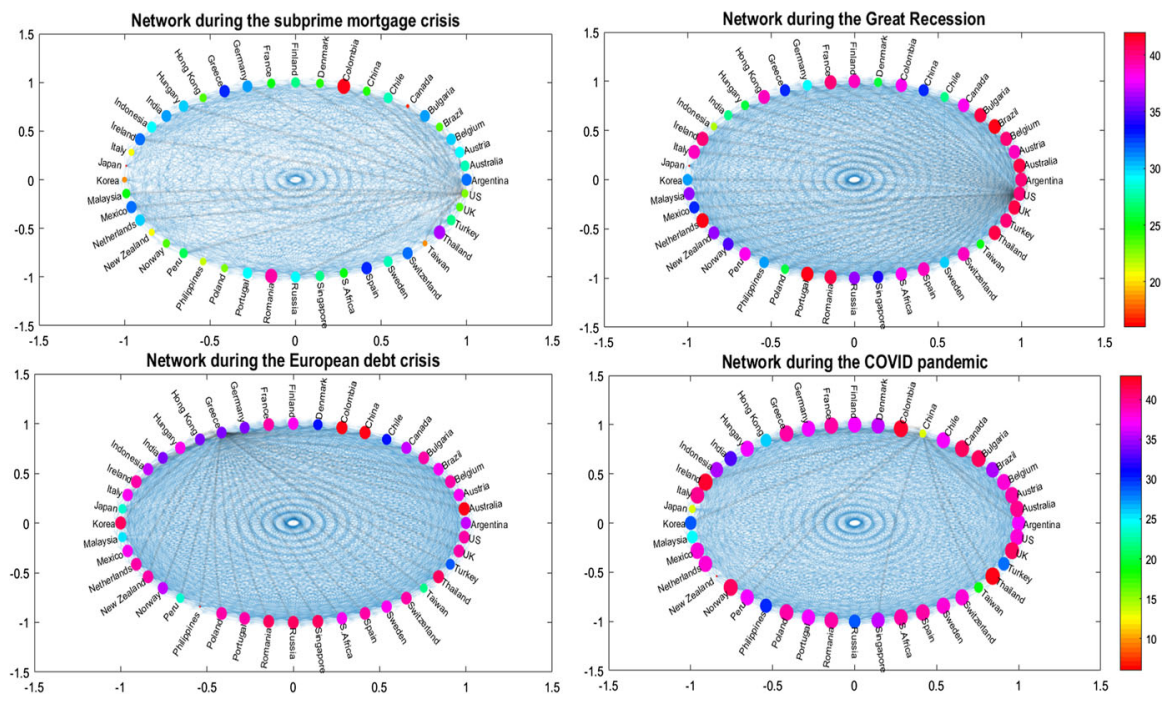

Fig. 2 Networks during the four episodes of crises from 2007 to 2021, which are (i) subprime mortgage crisis of 2007 to 2008, (ii) the Great Recession of 2008 to 2009, (iii) the European debt crisis of 2010 to 2013 and iv) the COVID pandemic of 2019 to 2021. The nodes are colored based on the strength of contagion using the joint contagion test in equation (17). If the node is colored in dark red, it reveals that all 43 recipient countries are affected by the source node, while if the node is colored in orange, it shows that no country is affected

regions, the European countries are the most dominant the source node in the network during the European debt crisis. Among the four crises, the connections are not strong during the subprime mortgage crisis, as evident by the total number of links and density being the lowest. 


\subsection{The determinants of crisis transmission}

Financial crisis indicators can provide important tools for both academics and policymakers in understanding the determinants of crisis transmission (Giordano et al. 2013). A number of papers analyze the ability of such indicators to anticipate financial crisis and assess the impact of financial crisis future vulnerabilities. Crisis indicators that have been studied in the literature include those related to equity and debt inflows (Didier et al. 2010), terms of trade (Forbes 2012), financial conditions (Dungey and Martin 2007; Matsuyama 2007; Cipriani et al. 2013; de Haas and van Horen 2013; and Morley 2016), regional proximity (Glick and Rose 1999; Dungey et al. 2009) and development comparability (Fry-McKibbin et al. 2014). In this paper, we mainly focus on the following conditions: (i) debt levels include public, private and external debts, (ii) fiscal and current accounts, (iii) regional proximity and (iv) stage of economic development. The crisis indicators are further analyzed in Appendix E.

In order to test whether the crisis indicators discussed above can be treated as an important predictor in explaining contagion, a crisis severity index is constructed with two groups such as high-debt and low-debt. There are several steps to compute the crisis severity index $\left(C I_{t}\right)$. First, taking the pre-crisis $\left(T_{1, x}=661\right)$ period as fixed, the crisis period is defined on a rolling sample basis using a window length of 30 days, where the crisis period shifts forward by one day between each rolling sample. Second, all test statistics $\left(M T_{t}\right)$ in equation (17) can be computed for each rolling sample. Finally, the crisis severity index $\left(C I_{t}\right)$ can be computed by using capitalization-weighted index of indicator variable. If the multiple-channel test statistic $\left(M T_{t}\right)$ at time $t$ is greater than the critical value 9.49 , the indicator $\left(I_{(i \rightarrow j), j, t}\right)$ at time $t$ takes a value of 1 , indicating market contagion from source country $i$ to a recipient country $j$ at the $5 \%$ significant level, such that

$$
I_{(i \rightarrow j), j, t}=\left\{\begin{array}{l}
1: M T_{t}>9.49 \\
0: \text { otherwise }
\end{array}, i \neq j .\right.
$$

Then, the crisis severity index $\left(C I_{t}\right)$ at time $t$ is given by

$$
C I_{t}=100 .\left(\frac{\sum_{j=1}^{43} C W_{j} \times I_{(i \rightarrow j), j, t}}{43}\right), i \neq j,
$$

where $C W_{j}$ is the market capitalization (cap) weight for the recipient country $j$. The index is constructed in terms of market cap value, so that the countries with large market cap value will carry more weight in the calculation of the index. ${ }^{9}$

To understand why some countries are more affected by the crisis than others, we conduct a difference-in-means $t$ test for different country groupings. Taking the debt-to-GDP ratio as an example, if a country's debt ratio is above the 80th percentile of its distribution, the country will be classified in the "high-debt" group, while if a country's ratio is below the 20 th percentile, the country will be classified in the "low-

\footnotetext{
9 The market cap of selected 44 countries are shown in Appendix E.
} 
debt" group. ${ }^{10}$ In this case, the crisis severity index of the $n_{1}$ high-debt countries is calculated as

$$
C I_{1, t}=100\left(\frac{\sum_{j=1}^{n_{1}} C W_{j} \times I_{j, t}}{n_{1}}\right),
$$

while the crisis severity index for the the $n_{2}$ low-debt countries is given by

$$
C I_{2, t}=100\left(\frac{\sum_{j=1}^{n_{2}} C W_{j} \times I_{j, t}}{n_{2}}\right) .
$$

The independent two sample $t$ test statistic is given by

$$
t=\frac{\mu_{C I_{1}}-\mu_{C I_{2}}}{\sigma_{C I_{12}} \sqrt{\frac{1}{n_{1}}+\frac{1}{n_{2}}}},
$$

where

$$
\sigma_{C I_{12}}=\sqrt{\frac{\sigma_{C I_{1}}^{2}\left(n_{1}-1\right)+\sigma_{C I_{2}}^{2}\left(n_{2}-1\right)}{n_{1}+n_{2}-2}} .
$$

Here, $\mu_{C I_{1}}$ and $\mu_{C I_{2}}$ are the sample means of crisis severity index for high-debt and low-debt groups in equations (22) and (23), $\sigma_{C I_{1}}^{2}$ and $\sigma_{C I_{2}}^{2}$ are the sample variances of the crisis severity index for two groups, and $\sigma_{C I_{12}}$ is the pooled standard deviation.

The null and alternative hypotheses of no difference of crisis transmission between the high-debt and low-debt groups are

$$
\begin{aligned}
& H_{0}: \mu_{C I_{1}} \leq \mu_{C I_{2}}, \\
& H_{1}: \mu_{C I_{1}}>\mu_{C I_{2}},
\end{aligned}
$$

Under the null hypothesis of no crisis transmission through the link arising from the similar debt conditions, the $t$ statistic is asymptotically distributed as $T_{n_{1}+n_{2}-2}$.

Figure 3 displays results for crisis severity indices related to economic conditions during the three episodes of financial crises of 2007 to 2013. The first row of Figure 3 shows the percentage of countries affected by contagion in terms of the debt conditions (the public, private and external debt) over the three episodes of crisis from 2007 to 2013. The solid (black) line presents the 30 day indicator of contagion for the highdebt countries in (22), and the dotted (red) line for the low-debt countries in (23). As the public debt panel shows, the subprime mortgage crisis and the Great Recession crisis affect nearly $10 \%$ of low-debt and high-debt countries; while the European debt crisis affect more on high-debt countries (40\%) than the low-debt countries (10\%). For the private debt panel, the results reveal that the crisis severity index for the highdebt countries are much higher than that for the low-debt countries during the three

\footnotetext{
10 As the threshold of high- and low-debt groups is selected arbitrarily, we also consider the 70th and 60th percentiles for the robustness check. The results based on 70th and 60th percentiles are very similar to those of using 80th percentile in high-debt group.
} 
crises. As for external debt panel, the results show that the crisis severity index for the high-debt countries is quite identical to the low-debt countries during the three crises.

The second row of Figure 3 shows crisis severity indices related to fiscal and current account balances. The solid (black) line presents the 30-day indicator of contagion for the weak-account countries in (22), and the dotted (red) line for the strong-account countries in (23). As the fiscal account panel shows, the European debt crisis affected fiscally weak countries (40\%) more than strong countries (10\%), while the subprime mortgage crisis and the Great Recession crisis tend to affect a small number of fiscal weak or strong countries. Compared with the role of fiscal account balance in detecting contagion, the current account is less likely to be correlated with crisis transmission during the three financial crises, with little difference of incidence of crisis severity between fiscally strong and weak countries. For both account balances, only the European debt crisis affects weak countries (40\%) more than strong countries (10\%), but the crisis severity index is quite similar for both of groups during the US-sourced crises.

The last row of Fig. 3 show the percentage of countries affected by contagion in terms of regional proximity (Americas, Asia, Africa and Europe) and development comparability (developed and emerging) over the three episodes of crisis. For the regional panel, the countries most affected by contagion are located in the European region (40\%), followed by the Asian and Americas regions (20\%). Turning to the development comparability panel, the results show that developed and emerging countries in North and South America show similar crisis rates during the subprime mortgage crisis and the Great Recession, suggesting little support for development comparability in driving crisis transmission. However, the results are different from the European debt crisis, where the crisis affects the developed European countries $(20 \%)$ more than the emerging countries $(5 \%)$.

Table 10 presents difference-in-means test results for different country groupings based on the eight economic indicators for crisis transmission during the three financial crises from 2007 to 2013 . The results reveal that the debt conditions play an important role in explaining the crisis transmission for three episodes of financial crises of 2007 to 2013. In particular, among the three types of debt, private debt is the most important indicator, followed by public and external debts during the three financial crises. Not only are debt conditions important, but so is the fiscal account balance, as is evident by crisis severity index for weak-balance countries being significantly larger than for strong-balance countries at a 5\% significance level. Compared with the role of fiscal account balance, the current account balance appears not to be an important indicator in explaining the crisis transmission, as there is no significant evidence of crisis transmission for both weak- and strong-balance countries during the entire crisis period of 2007 to 2013.

In terms of regional linkages, the results of Table 10 suggest that the European debt crisis displayed evidence of regional contagion, but the subprime mortgage crisis and the Great Recession crisis did not. In particular, it is evident that the mean of crisis severity index for the European countries is significantly higher than other countries in African, Americas and Asian regions at the 5\% significance level. Regarding to similar levels of development, the results suggest that development comparability plays an 
Public debt

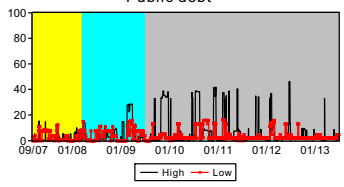

Fiscal account balance
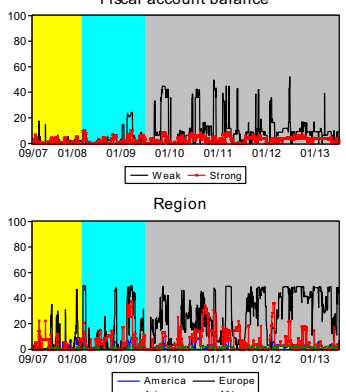

Private debt

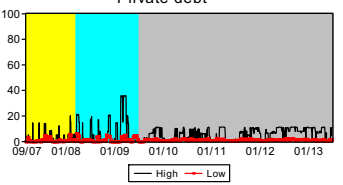

Current account balance
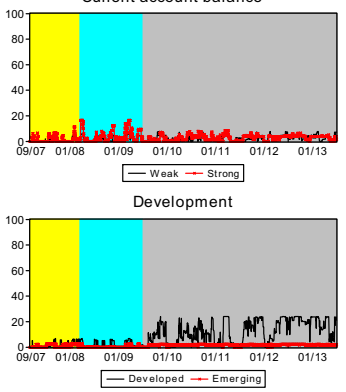

External debt

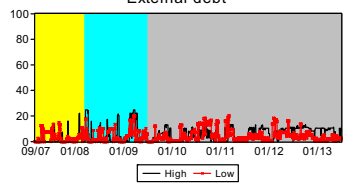

Both account balance

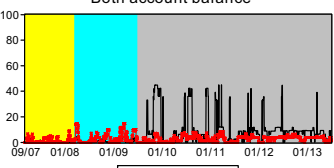

-Weak $\rightarrow$ Strong

Fig. 3 Percentage of countries affected by contagion related to debt, fiscal and current account conditions, regional linkages and development comparability for the three financial crises between 2007 to 2013 (Notes: The shaded areas refer to three episodes of financial crisis: (i) the subprime mortgage crisis (Sep 6, 2007 to Sep 12, 2008); (ii) the Great Recession (Sep 15, 2008 to Dec 31, 2009); and (iii) the European debt crisis (Feb 12, 2010 to Dec 31, 2013). The countries in the high-debt group (High) and the low-debt group (Low). The countries in the weak-balance group (Weak) and the strong-balance strong (Strong). The countries in four regions (Africa, Americas, Asia and Europe). The countries in the development type (Developed/Emerging). The crisis severity index for two groups are calculated in equations (22) and (23).)

important role in explaining the crisis transmission in the Great Recession crisis and the European debt crisis, but not in the subprime mortgage crisis.

\section{Conclusions}

In this paper, we have developed a new test of financial market contagion to identify why financial shocks spread across international markets. Contagion is defined as a significant changes in second and higher-order co-moments including correlation, coskewness and co-volatility for two markets between a non-crisis and a crisis period. Our proposed test enables us to simultaneously capture these various channels of contagion (i) from mean returns of the source market to mean returns of the recipient market; (ii) from the mean returns of the source market to return volatility of the recipient market; (iii) from return volatility of the source market to mean returns of the recipient market; and (iv) from return volatility of the source market to return volatility of the recipient market.

In deriving a new multiple-channel test of contagion, we considered a bivariate generalized exponential distribution and employed a Lagrange multiplier test. In comparison with existing single-channel tests, our proposed test appears to provide a good approximation of the finite-sample distribution given the relatively large sample period of the non-crisis but the relatively short sample period of the crisis. 


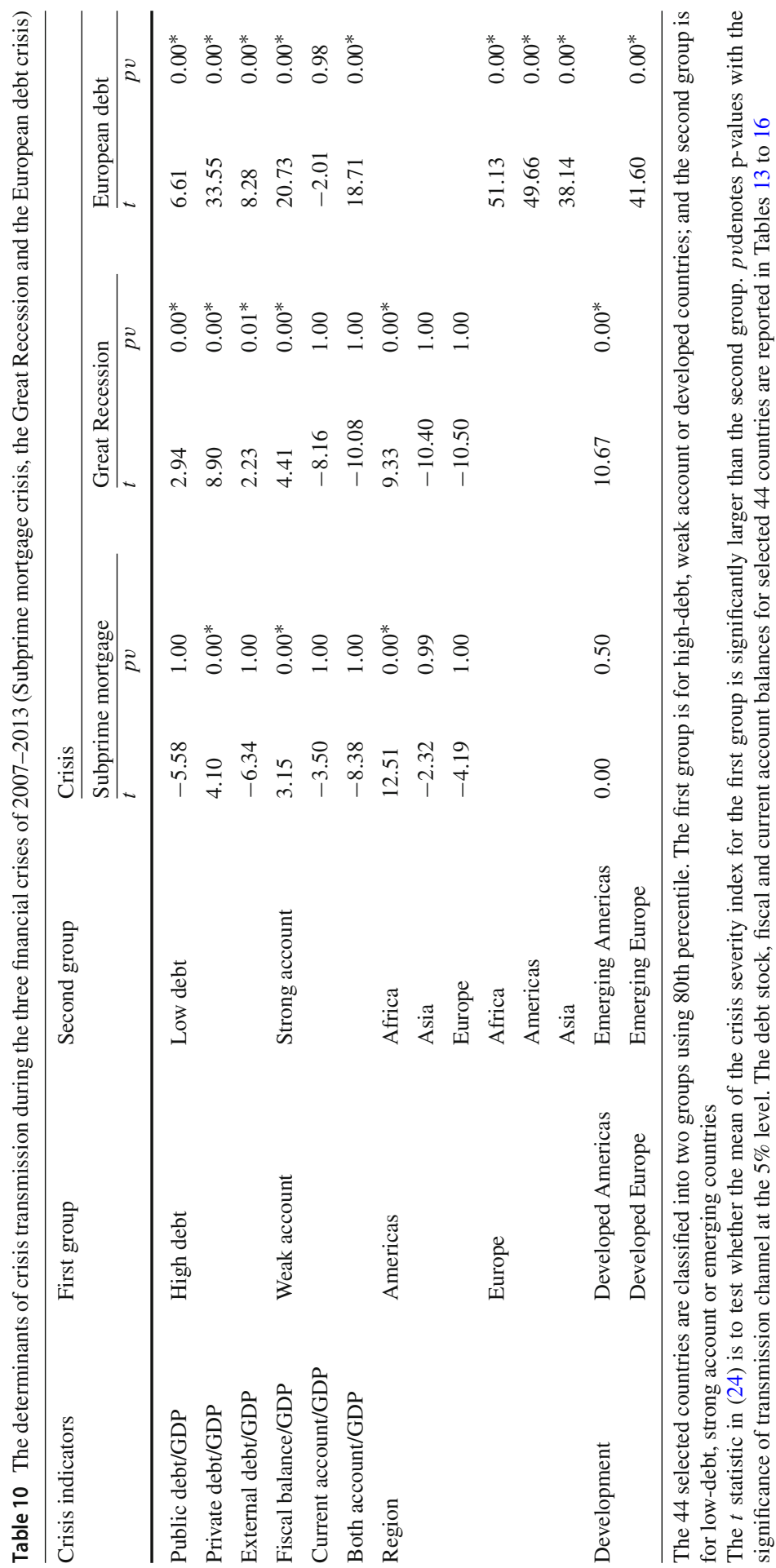


Our new test is applied to investigate financial market contagion in equity markets during the four episodes of financial crisis from 2007 to 2021. The results suggest widespread contagion from the US to global equity markets during the subprime mortgage crisis and the Great Recession, from Greece to global equity markets during the European debt crisis and from China to global equity markets during the COVID pandemic. Among the four financial crises, the Great Recession crisis seems to have been the most pervasive, followed by the European debt crisis and the COVID pandemic, with the subprime mortgage crisis the least pervasive. Using network analysis where all possible contagion effects are considered, it is evident that the networks for the COVID pandemic are the most connected, followed by the Great Recession and the European debt crisis, while the connections are not strong for the subprime mortgage crisis.

In investigating possible reasons for contagion, including levels of different types of debt, regional proximity and stage of development, we constructed crisis severity indices and found that, for the crises between 2007 and 2013, similar debt characteristics played the main role in explaining the transmission of a crisis from one country to another. Among the three types of debt that we consider, private debt is the most important. However, public debt is also an important indicator in driving crisis, especially for the European debt crisis. This result is consistent with the results in Reinhart and Rogoff (2011a, 2011b) that public debts rise markedly as a sovereign debt crisis draws near. Of course, the importance of regional linkages is also important during the European sovereign debt crisis.

Acknowledgements We thank Yu-wei Luke Chu, Alan King, Robert Kirkby, Ilan Noy, Anella Munro, Yigit Saglam, Benjamin Wong and participants of the Brown Bag Seminar Series at Victoria University of Wellington, University of Otago, the Reserve Bank of New Zealand, the Society of Nonlinear Dynamics and Econometrics 23rd annual symposium, and the Society for Computational Economics and Finance 21 st international conference. Hsiao and Morley acknowledge funding from the Macau SAR Government Higher Education Fund and ARC Grant DP130102950.

\section{Declarations}

Conflict of interest The authors declare that they have no conflicts of interest.

Ethical approval This article does not contain any studies with human participants or animals performed by any of the authors.

\section{A Appendix}

This appendix contains four sections. Section B presents the results of information matrix derivations used for test statistic of joint co-moments. Section $\mathrm{C}$ presents the details of derivation for test statistic of joint co-moments. Section D conducts the sensitivity analysis of contagion tests by using Bai and Perron (2003) structural break tests to identify the pre-crisis and crisis dates. Section E provides the discussion of financial crisis indicators used in this paper. 


\section{B Information matrix derivations}

The following results are used to derive the information matrix for the test statistic of joint correlation, co-skewness and co-volatility. Consider the following bivariate normal distribution with higher-order co-moments

$$
\begin{aligned}
h= & -\frac{1}{2}\left(\frac{1}{1-\rho^{2}}\right)\left(\left(\frac{r_{1, t}-\mu_{1}}{\sigma_{1}}\right)^{2}+\left(\frac{r_{2, t}-\mu_{2}}{\sigma_{2}}\right)^{2}-2 \rho\left(\frac{r_{1, t}-\mu_{1}}{\sigma_{1}}\right)\left(\frac{r_{2, t}-\mu_{2}}{\sigma_{2}}\right)\right) \\
& +\theta_{4}\left(\frac{r_{1, t}-\mu_{1}}{\sigma_{1}}\right)^{1}\left(\frac{r_{2, t}-\mu_{2}}{\sigma_{2}}\right)^{2}+\theta_{5}\left(\frac{r_{1, t}-\mu_{1}}{\sigma_{1}}\right)^{2}\left(\frac{r_{2, t}-\mu_{2}}{\sigma_{2}}\right)^{1} \\
& +\theta_{6}\left(\frac{r_{1, t}-\mu_{1}}{\sigma_{1}}\right)^{2}\left(\frac{r_{2, t}-\mu_{2}}{\sigma_{2}}\right)^{2} .
\end{aligned}
$$

We take the expectations of the first and second conditions of the distribution with respect to the parameters $\left(\mu_{1}, \mu_{2}, \sigma_{1}^{2}, \sigma_{2}^{2}, \rho, \theta_{4}, \theta_{5}\right.$ and $\left.\theta_{6}\right)$ in (25) under the null hypothesis of independent bivariate normality, then the following elements of the information matrix at observation $t$ are

$$
\begin{aligned}
& I_{1,1, t}=E\left[\left(\frac{\partial h}{\partial \mu_{1}}\right)^{2}\right]-E\left[\frac{\partial h}{\partial \mu_{1}}\right] E\left[\frac{\partial h}{\partial \mu_{1}}\right]=\frac{1}{\sigma_{1}^{2}}, \\
& I_{1,2, t}=E\left[\frac{\partial h}{\partial \mu_{1}} \frac{\partial h}{\partial \mu_{2}}\right]-E\left[\frac{\partial h}{\partial \mu_{1}}\right] E\left[\frac{\partial h}{\partial \mu_{2}}\right]=0, \\
& I_{1,3, t}=E\left[\frac{\partial h}{\partial \mu_{1}} \frac{\partial h}{\partial \sigma_{1}^{2}}\right]-E\left[\frac{\partial h}{\partial \mu_{1}}\right] E\left[\frac{\partial h}{\partial \sigma_{1}^{2}}\right]=0, \\
& I_{1,4, t}=E\left[\frac{\partial h}{\partial \mu_{1}} \frac{\partial h}{\partial \sigma_{2}^{2}}\right]-E\left[\frac{\partial h}{\partial \mu_{1}}\right] E\left[\frac{\partial h}{\partial \sigma_{2}^{2}}\right]=0, \\
& I_{1,5, t}=E\left[\frac{\partial h}{\partial \mu_{1}} \frac{\partial h}{\partial \rho}\right]-E\left[\frac{\partial h}{\partial \mu_{1}}\right] E\left[\frac{\partial h}{\partial \rho}\right]=0, \\
& I_{1,6, t}=E\left[\frac{\partial h}{\partial \mu_{1}} \frac{\partial h}{\partial \theta_{4}}\right]-E\left[\frac{\partial h}{\partial \mu_{1}}\right] E\left[\frac{\partial h}{\partial \theta_{4}}\right]=\frac{1}{\sigma_{1}}, \\
& I_{1,7, t}=E\left[\frac{\partial h}{\partial \mu_{1}} \frac{\partial h}{\partial \theta_{5}}\right]-E\left[\frac{\partial h}{\partial \mu_{1}}\right] E\left[\frac{\partial h}{\partial \theta_{5}}\right]=0, \\
& I_{1,8, t}=E\left[\frac{\partial h}{\partial \mu_{1}} \frac{\partial h}{\partial \theta_{6}}\right]-E\left[\frac{\partial h}{\partial \mu_{1}}\right] E\left[\frac{\partial h}{\partial \theta_{6}}\right]=0, \\
& I_{2,2, t}=E\left[\left(\frac{\partial h}{\partial \mu_{2}}\right)^{2}\right]-E\left[\frac{\partial h}{\partial \mu_{2}}\right] E\left[\frac{\partial h}{\partial \mu_{2}}\right]=\frac{1}{\sigma_{2}^{2}}, \\
& {\left[\frac{\partial h}{\partial \mu_{2}} \frac{\partial h}{\partial \sigma_{1}^{2}}\right]-E\left[\frac{\partial h}{\partial \mu_{2}}\right] E\left[\frac{\partial h}{\partial \sigma_{1}^{2}}\right]=0,}
\end{aligned}
$$




$$
\begin{aligned}
& I_{2,4, t}=E\left[\frac{\partial h}{\partial \mu_{2}} \frac{\partial h}{\partial \sigma_{2}^{2}}\right]-E\left[\frac{\partial h}{\partial \mu_{2}}\right] E\left[\frac{\partial h}{\partial \sigma_{2}^{2}}\right]=0, \\
& I_{2,5, t}=E\left[\frac{\partial h}{\partial \mu_{2}} \frac{\partial h}{\partial \rho}\right]-E\left[\frac{\partial h}{\partial \mu_{2}}\right] E\left[\frac{\partial h}{\partial \rho}\right]=0 \text {, } \\
& I_{2,6, t}=E\left[\frac{\partial h}{\partial \mu_{2}} \frac{\partial h}{\partial \theta_{4}}\right]-E\left[\frac{\partial h}{\partial \mu_{2}}\right] E\left[\frac{\partial h}{\partial \theta_{4}}\right]=0, \\
& I_{2,7, t}=E\left[\frac{\partial h}{\partial \mu_{2}} \frac{\partial h}{\partial \theta_{5}}\right]-E\left[\frac{\partial h}{\partial \mu_{2}}\right] E\left[\frac{\partial h}{\partial \theta_{5}}\right]=\frac{1}{\sigma_{2}}, \\
& I_{2,8, t}=E\left[\frac{\partial h}{\partial \mu_{2}} \frac{\partial h}{\partial \theta_{6}}\right]-E\left[\frac{\partial h}{\partial \mu_{2}}\right] E\left[\frac{\partial h}{\partial \theta_{6}}\right]=0 \text {, } \\
& I_{3,3, t}=E\left[\left(\frac{\partial h}{\partial \sigma_{1}^{2}}\right)^{2}\right]-E\left[\frac{\partial h}{\partial \sigma_{1}^{2}}\right] E\left[\frac{\partial h}{\partial \sigma_{1}^{2}}\right]=\frac{1}{2 \sigma_{1}^{4}}, \\
& I_{3,4, t}=E\left[\frac{\partial h}{\partial \sigma_{1}^{2}} \frac{\partial h}{\partial \sigma_{2}^{2}}\right]-E\left[\frac{\partial h}{\partial \sigma_{1}^{2}}\right] E\left[\frac{\partial h}{\partial \sigma_{2}^{2}}\right]=0 \text {, } \\
& I_{3,5, t}=E\left[\frac{\partial h}{\partial \sigma_{1}^{2}} \frac{\partial h}{\partial \rho}\right]-E\left[\frac{\partial h}{\partial \sigma_{1}^{2}}\right] E\left[\frac{\partial h}{\partial \rho}\right]=0, \\
& I_{3,6, t}=E\left[\frac{\partial h}{\partial \sigma_{1}^{2}} \frac{\partial h}{\partial \theta_{4}}\right]-E\left[\frac{\partial h}{\partial \sigma_{1}^{2}}\right] E\left[\frac{\partial h}{\partial \theta_{4}}\right]=0, \\
& I_{3,7, t}=E\left[\frac{\partial h}{\partial \sigma_{1}^{2}} \frac{\partial h}{\partial \theta_{5}}\right]-E\left[\frac{\partial h}{\partial \sigma_{1}^{2}}\right] E\left[\frac{\partial h}{\partial \theta_{5}}\right]=0, \\
& I_{3,8, t}=E\left[\frac{\partial h}{\partial \sigma_{1}^{2}} \frac{\partial h}{\partial \theta_{6}}\right]-E\left[\frac{\partial h}{\partial \sigma_{1}^{2}}\right] E\left[\frac{\partial h}{\partial \theta_{6}}\right]=\frac{1}{\sigma_{1}^{2}}, \\
& I_{4,4, t}=E\left[\left(\frac{\partial h}{\partial \sigma_{1}^{2}}\right)^{2}\right]-E\left[\frac{\partial h}{\partial \sigma_{1}^{2}}\right] E\left[\frac{\partial h}{\partial \sigma_{1}^{2}}\right]=\frac{1}{2 \sigma_{2}^{4}}, \\
& I_{4,5, t}=E\left[\frac{\partial h}{\partial \sigma_{1}^{2}} \frac{\partial h}{\partial \sigma_{2}^{2}}\right]-E\left[\frac{\partial h}{\partial \sigma_{1}^{2}}\right] E\left[\frac{\partial h}{\partial \sigma_{2}^{2}}\right]=0 \text {, } \\
& I_{4,6, t}=E\left[\frac{\partial h}{\partial \sigma_{2}^{2}} \frac{\partial h}{\partial \theta_{4}}\right]-E\left[\frac{\partial h}{\partial \sigma_{2}^{2}}\right] E\left[\frac{\partial h}{\partial \theta_{4}}\right]=0 \text {, } \\
& I_{4,7, t}=E\left[\frac{\partial h}{\partial \sigma_{2}^{2}} \frac{\partial h}{\partial \theta_{5}}\right]-E\left[\frac{\partial h}{\partial \sigma_{2}^{2}}\right] E\left[\frac{\partial h}{\partial \theta_{5}}\right]=0, \\
& I_{4,8, t}=E\left[\frac{\partial h}{\partial \sigma_{2}^{2}} \frac{\partial h}{\partial \theta_{6}}\right]-E\left[\frac{\partial h}{\partial \sigma_{2}^{2}}\right] E\left[\frac{\partial h}{\partial \theta_{6}}\right]=\frac{1}{\sigma_{2}^{2}},
\end{aligned}
$$




$$
\begin{aligned}
& I_{5,5, t}=E\left[\left(\frac{\partial h}{\partial \rho}\right)^{2}\right]-E\left[\frac{\partial h}{\partial \rho}\right] E\left[\frac{\partial h}{\partial \rho}\right]=1, \\
& I_{5,6, t}=E\left[\frac{\partial h}{\partial \rho} \frac{\partial h}{\partial \theta_{4}}\right]-E\left[\frac{\partial h}{\partial \rho}\right] E\left[\frac{\partial h}{\partial \theta_{4}}\right]=0, \\
& I_{5,7, t}=E\left[\frac{\partial h}{\partial \rho} \frac{\partial h}{\partial \theta_{5}}\right]-E\left[\frac{\partial h}{\partial \rho}\right] E\left[\frac{\partial h}{\partial \theta_{5}}\right]=0 \\
& I_{5,8, t}=E\left[\frac{\partial h}{\partial \rho} \frac{\partial h}{\partial \theta_{6}}\right]-E\left[\frac{\partial h}{\partial \rho}\right] E\left[\frac{\partial h}{\partial \theta_{6}}\right]=0, \\
& I_{6,6, t}=E\left[\frac{\partial h}{\partial \theta_{4}} \frac{\partial h}{\partial \theta_{4}}\right]-E\left[\frac{\partial h}{\partial \theta_{4}}\right] E\left[\frac{\partial h}{\partial \theta_{4}}\right]=3, \\
& I_{6,7, t}=E\left[\frac{\partial h}{\partial \theta_{4}} \frac{\partial h}{\partial \theta_{5}}\right]-E\left[\frac{\partial h}{\partial \theta_{4}}\right] E\left[\frac{\partial h}{\partial \theta_{5}}\right]=0, \\
& I_{6,8, t}=E\left[\frac{\partial h}{\partial \theta_{4}} \frac{\partial h}{\partial \theta_{6}}\right]-E\left[\frac{\partial h}{\partial \theta_{4}}\right] E\left[\frac{\partial h}{\partial \theta_{6}}\right]=0, \\
& I_{7,7, t}=E\left[\frac{\partial h}{\partial \theta_{5}} \frac{\partial h}{\partial \theta_{5}}\right]-E\left[\frac{\partial h}{\partial \theta_{5}}\right] E\left[\frac{\partial h}{\partial \theta_{5}}\right]=3, \\
& I_{7,8, t}=E\left[\frac{\partial h}{\partial \theta_{5}} \frac{\partial h}{\partial \theta_{6}}\right]-E\left[\frac{\partial h}{\partial \theta_{5}}\right] E\left[\frac{\partial h}{\partial \theta_{6}}\right]=0, \\
& I_{8,8, t}=E\left[\frac{\partial h}{\partial \theta_{6}} \frac{\partial h}{\partial \theta_{6}}\right]-E\left[\frac{\partial h}{\partial \theta_{6}}\right] E\left[\frac{\partial h}{\partial \theta_{6}}\right]=8,
\end{aligned}
$$

where

$$
\begin{aligned}
& \mu_{i}=E\left[r_{i, t}\right], \\
& E\left[\left(\frac{r_{i, t}-\mu_{i}}{\sigma_{i}}\right)^{2}\right]=1, \\
& E\left[\left(\frac{r_{i, t}-\mu_{i}}{\sigma_{i}}\right)^{1}\left(\frac{r_{j, t}-\mu_{j}}{\sigma_{j}}\right)^{1}\right]=0, i \neq j, \\
& E\left[\left(\frac{r_{i, t}-\mu_{i}}{\sigma_{i}}\right)^{1}\left(\frac{r_{j, t}-\mu_{j}}{\sigma_{j}}\right)^{2}\right]=0, \\
& E\left[\left(\frac{r_{i, t}-\mu_{i}}{\sigma_{i}}\right)^{2}\left(\frac{r_{j, t}-\mu_{j}}{\sigma_{j}}\right)^{3}\right]=0 \text {, } \\
& E\left[\left(\frac{r_{i, t}-\mu_{i}}{\sigma_{i}}\right)^{3}\right]=0, \\
& E\left[\left(\frac{r_{i, t}-\mu_{i}}{\sigma_{i}}\right)^{2}\left(\frac{r_{j, t}-\mu_{j}}{\sigma_{j}}\right)^{2}\right]=1,
\end{aligned}
$$




$$
E\left[\left(\frac{r_{i, t}-\mu_{i}}{\sigma_{i}}\right)^{3}\left(\frac{r_{j, t}-\mu_{j}}{\sigma_{j}}\right)^{3}\right]=0
$$

\section{Test statistic for correlation, co-skewness and co-volatility}

Consider the following bivariate normal distribution with higher-order co-moments given as

$$
\begin{aligned}
f\left(r_{1, t}, r_{2, t}\right)= & \exp \left[-\frac{1}{2}\left(\frac{1}{1-\rho^{2}}\right)\left(\left(\frac{r_{1, t}-\mu_{1}}{\sigma_{1}}\right)^{2}+\left(\frac{r_{2, t}-\mu_{2}}{\sigma_{2}}\right)^{2}\right.\right. \\
& \left.-2 \rho\left(\frac{r_{1, t}-\mu_{1}}{\sigma_{1}}\right)\left(\frac{r_{2, t}-\mu_{2}}{\sigma_{2}}\right)\right) \\
& +\theta_{4}\left(\frac{r_{1, t}-\mu_{1}}{\sigma_{1}}\right)\left(\frac{r_{2, t}-\mu_{2}}{\sigma_{2}}\right)^{2}+\theta_{5}\left(\frac{r_{1, t}-\mu_{1}}{\sigma_{1}}\right)^{2}\left(\frac{r_{2, t}-\mu_{2}}{\sigma_{2}}\right) \\
& \left.+\theta_{6}\left(\frac{r_{1, t}-\mu_{1}}{\sigma_{1}}\right)^{2}\left(\frac{r_{2, t}-\mu_{2}}{\sigma_{2}}\right)^{2}-\eta\right],
\end{aligned}
$$

where

$$
\begin{aligned}
\eta= & \ln \iint \exp \left[-\frac{1}{2}\left(\frac{1}{1-\rho^{2}}\right)\left(\left(\frac{r_{1, t}-\mu_{1}}{\sigma_{1}}\right)^{2}+\left(\frac{r_{2, t}-\mu_{2}}{\sigma_{2}}\right)^{2}\right.\right. \\
& \left.-2 \rho\left(\frac{r_{1, t}-\mu_{1}}{\sigma_{1}}\right)\left(\frac{r_{2, t}-\mu_{2}}{\sigma_{2}}\right)\right) \\
& +\theta_{4}\left(\frac{r_{1, t}-\mu_{1}}{\sigma_{1}}\right)\left(\frac{r_{2, t}-\mu_{2}}{\sigma_{2}}\right)^{2}+\theta_{5}\left(\frac{r_{1, t}-\mu_{1}}{\sigma_{1}}\right)^{2}\left(\frac{r_{2, t}-\mu_{2}}{\sigma_{2}}\right) \\
& \left.+\theta_{6}\left(\frac{r_{1, t}-\mu_{1}}{\sigma_{1}}\right)^{2}\left(\frac{r_{2, t}-\mu_{2}}{\sigma_{2}}\right)^{2}\right] d r_{1} d r_{2}, \\
= & \ln \iint \exp [h] d r_{1} d r_{2},
\end{aligned}
$$

and $h$ in (25).

The multiple-channel test of contagion based on changes in correlation, coskewness and co-volatility in equation (12) is based on the null hypothesis

$$
H_{0}: \rho=0, \theta_{4}=0, \theta_{5}=0, \theta_{6}=0,
$$

Under the null hypothesis of independence and bivariate normality, the maximum likelihood estimators of the unknown parameters are simply

$$
\widehat{\mu}_{i}=\frac{1}{T} \sum_{t} r_{i, t} ; \widehat{\sigma}_{i}^{2}=\frac{1}{T} \sum_{t}\left(r_{i, t}-\widehat{\mu}_{i}\right)^{2} ; \forall i=1,2,
$$


Let the parameters of (26) to be $\Theta=\left\{\mu_{1}, \mu_{2}, \sigma_{1}^{2}, \sigma_{2}^{2}, \theta_{4}, \theta_{5}, \theta_{6}\right\}$. By taking the log function of (26), the log likelihood function at time $t$ is given by

$$
\begin{aligned}
\ln L_{t}(\Theta)= & -\frac{1}{2}\left(\frac{1}{1-\rho^{2}}\right)\left(\left(\frac{r_{1, t}-\mu_{1}}{\sigma_{1}}\right)^{2}+\left(\frac{r_{2, t}-\mu_{2}}{\sigma_{2}}\right)^{2}-2 \rho\left(\frac{r_{1, t}-\mu_{1}}{\sigma_{1}}\right)\left(\frac{r_{2, t}-\mu_{2}}{\sigma_{2}}\right)\right) \\
& +\theta_{4}\left(\frac{r_{1, t}-\mu_{1}}{\sigma_{1}}\right)\left(\frac{r_{2, t}-\mu_{2}}{\sigma_{2}}\right)^{2}+\theta_{5}\left(\frac{r_{1, t}-\mu_{1}}{\sigma_{1}}\right)^{2}\left(\frac{r_{2, t}-\mu_{2}}{\sigma_{2}}\right) \\
& +\theta_{6}\left(\frac{r_{1, t}-\mu_{1}}{\sigma_{1}}\right)^{2}\left(\frac{r_{2, t}-\mu_{2}}{\sigma_{2}}\right)^{2}-\eta .
\end{aligned}
$$

Using (5) and the results of Appendix $\mathrm{B}$, the information matrix under the null hypothesis $\left(H_{0}: \rho=0, \theta_{4}=0, \theta_{5}=0, \theta_{6}=0\right)$ is

$$
\begin{aligned}
I(\Theta)=T \times\left(E\left[\frac{\partial h}{\partial \Theta} \frac{\partial h}{\partial \Theta^{\prime}}\right]-E\left[\frac{\partial h}{\partial \Theta}\right] E\left[\frac{\partial h}{\partial \Theta^{\prime}}\right]\right) \mid \cdot \rho=\theta_{4}=\theta_{5}=\theta_{6}=0 \\
=T \times\left[\begin{array}{cccccccc}
\frac{1}{\sigma_{1}^{2}} & 0 & 0 & 0 & 0 & \frac{1}{\sigma_{1}} & 0 & 0 \\
0 & \frac{1}{\sigma_{2}^{2}} & 0 & 0 & 0 & 0 & \frac{1}{\sigma_{2}} & 0 \\
0 & 0 & \frac{1}{2 \sigma_{1}^{4}} & 0 & 0 & 0 & 0 & \frac{1}{\sigma_{1}^{2}} \\
0 & 0 & 0 & \frac{1}{2 \sigma_{2}^{4}} & 0 & 0 & 0 & \frac{1}{\sigma_{2}^{2}} \\
0 & 0 & 0 & 0 & 1 & 0 & 0 & 0 \\
\frac{1}{\sigma_{1}} & 0 & 0 & 0 & 0 & 3 & 0 & 0 \\
0 & \frac{1}{\sigma_{2}} & 0 & 0 & 0 & 0 & 3 & 0 \\
0 & 0 & \frac{1}{\sigma_{1}^{2}} & \frac{1}{\sigma_{2}^{2}} & 0 & 0 & 0 & 8
\end{array}\right]
\end{aligned}
$$

where the elements of $I_{i, j}$ at observation $t$ are shown in Appendix B. Replacing the unknown population parameters by consistent estimators under the null hypothesis, the inverse asymptotic information matrix is

$$
I^{-1}(\widehat{\Theta})=\frac{1}{T}\left[\begin{array}{cccccccc}
\frac{1}{\widehat{\sigma}_{1}^{2}} & 0 & 0 & 0 & 0 & \frac{1}{\widehat{\sigma}_{1}} & 0 & 0 \\
0 & \frac{1}{\widehat{\sigma}_{2}^{2}} & 0 & 0 & 0 & 0 & \frac{1}{\widehat{\sigma}_{2}} & 0 \\
0 & 0 & \frac{1}{2 \widehat{\sigma}_{1}^{4}} & 0 & 0 & 0 & 0 & \frac{1}{\widehat{\sigma}_{1}^{2}} \\
0 & 0 & 0 & \frac{1}{2 \widehat{\sigma}_{2}^{4}} & 0 & 0 & 0 & \frac{1}{\widehat{\sigma}_{2}^{2}} \\
0 & 0 & 0 & 0 & 1 & 0 & 0 & 0 \\
\frac{1}{\widehat{\sigma}_{1}} & 0 & 0 & 0 & 0 & 3 & 0 & 0 \\
0 & \frac{1}{\widehat{\sigma}_{2}} & 0 & 0 & 0 & 0 & 3 & 0 \\
0 & 0 & \frac{1}{\widehat{\sigma}_{1}^{2}} & \frac{1}{\widehat{\sigma}_{2}^{2}} & 0 & 0 & 0 & 8
\end{array}\right]^{-1}
$$


Evaluating the gradients for $\rho, \theta_{4}, \theta_{5}$ and $\theta_{6}$ under the null hypothesis gives

$$
\begin{aligned}
& \frac{\partial \ln L_{t}(\Theta)}{\partial \rho}=\frac{1}{T} \sum_{t=1}^{T}\left(\frac{\partial h_{t}}{\partial \rho}\right)-\left(\frac{\partial \eta_{t}}{\partial \rho}\right) \\
& =\frac{1}{T} \sum_{t=1}^{T}\left(\frac{r_{1, t}-\mu_{1}}{\sigma_{1}}\right)\left(\frac{r_{2, t}-\mu_{2}}{\sigma_{2}}\right)-\left[E\left(\frac{\partial h_{t}}{\partial \rho}\right)\right] \\
& =\frac{1}{T} \sum_{t=1}^{T}\left(\frac{r_{1, t}-\mu_{1}}{\sigma_{1}}\right)\left(\frac{r_{2, t}-\mu_{2}}{\sigma_{2}}\right) \text {, } \\
& \frac{\partial \ln L_{t}(\Theta)}{\partial \theta_{4}}=\frac{1}{T} \sum_{t=1}^{T}\left(\frac{\partial h_{t}}{\partial \theta_{4}}\right)-\left(\frac{\partial \eta_{t}}{\partial \theta_{4}}\right) \\
& =\frac{1}{T} \sum_{t=1}^{T}\left(\frac{r_{1, t}-\mu_{1}}{\sigma_{1}}\right)^{1}\left(\frac{r_{2, t}-\mu_{2}}{\sigma_{2}}\right)^{2}, \\
& \frac{\partial \ln L_{t}(\Theta)}{\partial \theta_{5}}=\frac{1}{T} \sum_{t=1}^{T}\left(\frac{\partial h_{t}}{\partial \theta_{5}}\right)-\left(\frac{\partial \eta_{t}}{\partial \theta_{5}}\right) \\
& =\frac{1}{T} \sum_{t=1}^{T}\left(\frac{r_{1, t}-\mu_{1}}{\sigma_{1}}\right)^{2}\left(\frac{r_{2, t}-\mu_{2}}{\sigma_{2}}\right)^{1}, \\
& \frac{\partial \ln L_{t}(\Theta)}{\partial \theta_{6}}=\frac{1}{T} \sum_{t=1}^{T}\left(\frac{\partial h_{t}}{\partial \theta_{6}}\right)-\left(\frac{\partial \eta_{t}}{\partial \theta_{6}}\right) \\
& =\frac{1}{T} \sum_{t=1}^{T}\left(\frac{r_{1, t}-\mu_{1}}{\sigma_{1}}\right)^{2}\left(\frac{r_{2, t}-\mu_{2}}{\sigma_{2}}\right)^{2}-1 .
\end{aligned}
$$

The score function under $H_{0}$ is given as

$$
\begin{aligned}
& S(\widehat{\Theta})=\frac{\partial \ln L_{t}(\Theta)}{\partial \Theta} \mid \cdot \rho=\theta_{4}=\theta_{5}=\theta_{6}=0, \\
& =\left[\begin{array}{lllll}
0 & 0 & 0 & 0 & \frac{1}{T} \sum_{t=1}^{T}\left(\frac{r_{1, t}-\widehat{\mu}_{1}}{\widehat{\sigma}_{1}}\right)\left(\frac{r_{2, t}-\widehat{\mu}_{2}}{\widehat{\sigma}_{2}}\right)
\end{array}\right. \\
& \frac{1}{T} \sum_{t=1}^{T}\left(\frac{r_{1, t}-\widehat{\mu}_{1}}{\widehat{\sigma}_{1}}\right)^{1}\left(\frac{r_{2, t}-\widehat{\mu}_{2}}{\widehat{\sigma}_{2}}\right)^{2} \frac{1}{T} \sum_{t=1}^{T}\left(\frac{r_{1, t}-\widehat{\mu}_{1}}{\widehat{\sigma}_{1}}\right)^{2}\left(\frac{r_{2, t}-\widehat{\mu}_{2}}{\widehat{\sigma}_{2}}\right)^{1} \\
& \left.\frac{1}{T} \sum_{t=1}^{T}\left(\frac{r_{1, t}-\widehat{\mu}_{1}}{\widehat{\sigma}_{1}}\right)^{2}\left(\frac{r_{2, t}-\widehat{\mu}_{2}}{\widehat{\sigma}_{2}}\right)^{2}-1\right]^{\prime} .
\end{aligned}
$$


The Lagrange multiplier statistic is obtained by substituting (30) and (31) into (5), gives

$$
\begin{aligned}
L M= & T S(\widehat{\Theta})^{\prime} I(\widehat{\Theta})^{-1} S(\widehat{\Theta}) \\
= & \left(\frac{\frac{1}{T} \sum_{t=1}^{T}\left(\frac{r_{1, t}-\widehat{\mu}_{1}}{\widehat{\sigma}_{1}}\right)\left(\frac{r_{2, t}-\widehat{\mu}_{2}}{\widehat{\sigma}_{2}}\right)}{\sqrt{\frac{1}{T}}}\right)^{2}+\left(\frac{\frac{1}{T} \sum_{t=1}^{T}\left(\frac{r_{1, t}-\widehat{\mu}_{1}}{\widehat{\sigma}_{1}}\right)^{1}\left(\frac{r_{2, t}-\widehat{\mu}_{2}}{\widehat{\sigma}_{2}}\right)^{2}}{\sqrt{\frac{2}{T}}}\right)^{2} \\
& +\left(\frac{\frac{1}{T} \sum_{t=1}^{T}\left(\frac{r_{1, t}-\widehat{\mu}_{1}}{\widehat{\sigma}_{1}}\right)^{2}\left(\frac{r_{2, t}-\widehat{\mu}_{2}}{\widehat{\sigma}_{2}}\right)^{1}}{\sqrt{\frac{2}{T}}}\right)^{2}+\left(\frac{\frac{1}{T} \sum_{t=1}^{T}\left(\frac{r_{1, t}-\widehat{\mu}_{1}}{\widehat{\sigma}_{1}}\right)^{2}\left(\frac{r_{2, t}-\widehat{\mu}_{2}}{\widehat{\sigma}_{2}}\right)^{2}-1}{\sqrt{\frac{4}{T}}}\right)^{2} .
\end{aligned}
$$

\section{Sensitivity tests}

As contagion tests are conditional on a state of nature, the dating of a crisis period is an essential component of understanding contagion. We perform structural break tests(Bai and Perron 2003) to identify the non-crisis and crisis dates for sensitivity analysis. Table 11 shows structural break dates for residual returns and squared returns for 44 equity markets using the Bai and Perron (2003) test. The residuals are filtered by a VAR(5) during the period of 2005 to 2013. The results show that in terms of residual returns, most of countries show no structural break in mean during the period of 2005 to 2013. By analyzing the residual squared returns, the results reveal that among the 44 countries, 10 equity markets (Australia, Hong Kong, Korea, New Zealand, Singapore, Sweden, Switzerland, Taiwan, the UK and the US) have a structural break in variance in July, 2007, which is quite consistent with the break date on July 26, 2007 (FryMcKibbin et al. 2014).

In order to perform a further robustness check, we conduct sensitivity analysis by taking the dates as one-month before and after the break dates on July 25, 2007. Table 12 shows empirical results of contagion tests, given the pre-crisis period from January 1, 2005 to June 25, 2007 (Panel A) and from January 1, 2005 to August 25, 2007 (Panel B). The results reveal that among the three crises from 2007-13, the Great Recession seems to be the most pervasive crisis, followed by the European debt crisis, with the subprime mortgage crisis the least pervasive crisis. The results are consistent with the results in Tables 6,7 and 8 .

\section{E Financial crisis indicators}

This appendix provides the discussion of financial crisis indicators used in this paper. Four types of crisis indicators include (i) debt levels, (ii) fiscal and current accounts, (iii) regional proximity and (iv) stage of economic development. 


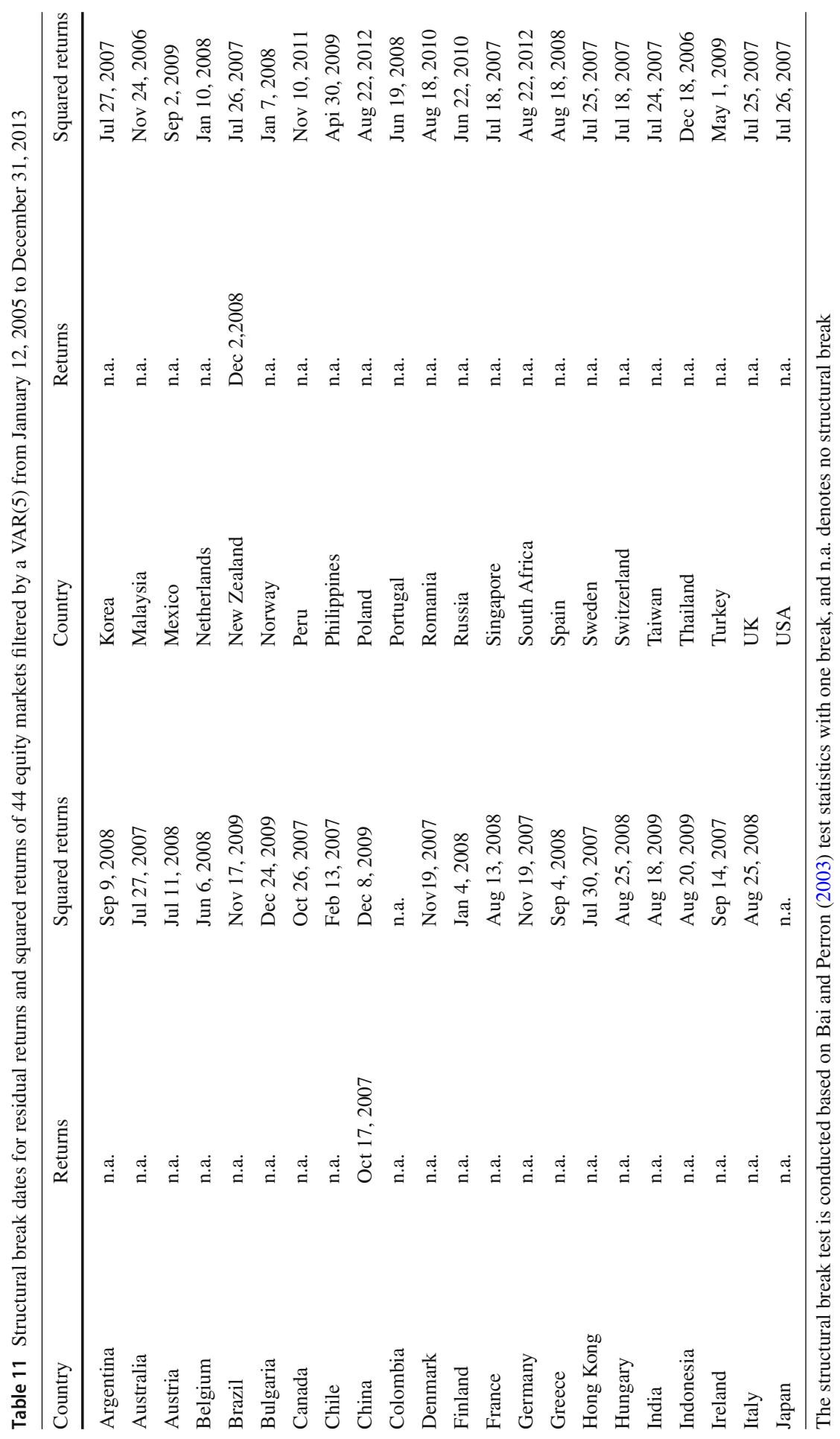


Table 12 Contagion tests based on changed in correlation, co-skewness and covolatility (MT) during the subprime mortgage crisis (SMC), the Great Recession (GRC) and the European debt crisis (EDC)

\begin{tabular}{|c|c|c|c|c|c|c|c|}
\hline \multirow[t]{2}{*}{ Region } & \multirow[t]{2}{*}{ Recipient $(j)$} & \multicolumn{3}{|c|}{ Panel A: Contagion tests } & \multicolumn{3}{|c|}{ Panel B: Contagion tests } \\
\hline & & SMC & GRC & EDC & SMC & GRC & $\mathrm{EDC}$ \\
\hline Africa & S. Africa & 1.13 & $77.36^{*}$ & $11.62^{*}$ & 1.51 & $88.43^{*}$ & $13.93^{*}$ \\
\hline \multirow[t]{8}{*}{ Americas } & Argentina & $30.36^{*}$ & $38.90^{*}$ & 6.40 & $33.37^{*}$ & $35.67^{*}$ & 6.39 \\
\hline & Brazil & $28.32^{*}$ & $58.27^{*}$ & 7.77 & $19.36^{*}$ & $71.98^{*}$ & $11.19^{*}$ \\
\hline & Canada & $10.23^{*}$ & $85.21^{*}$ & $18.85^{*}$ & 6.05 & $111.59^{*}$ & $27.17^{*}$ \\
\hline & Chile & $15.20^{*}$ & $22.00^{*}$ & $31.71^{*}$ & $9.79^{*}$ & $28.98^{*}$ & 3.63 \\
\hline & Colombia & $10.44^{*}$ & 2.45 & $336.10^{*}$ & $12.10^{*}$ & 3.93 & $343.31^{*}$ \\
\hline & Mexico & $13.81^{*}$ & $14.96^{*}$ & 1.65 & $15.28 *$ & $11.83^{*}$ & 2.76 \\
\hline & Peru & $26.33^{*}$ & $62.37^{*}$ & $15.90^{*}$ & $16.12^{*}$ & $78.55^{*}$ & 2.59 \\
\hline & USA & n.a. & n.a. & $58.96^{*}$ & n.a. & n.a. & $73.04^{*}$ \\
\hline \multirow[t]{13}{*}{ Asia } & Australia & 2.78 & $52.68^{*}$ & 6.04 & 4.34 & $80.47^{*}$ & $31.16^{*}$ \\
\hline & China & $28.85^{*}$ & $22.25^{*}$ & $16.74^{*}$ & $36.13^{*}$ & $30.29^{*}$ & $13.10^{*}$ \\
\hline & Hong Kong & 5.28 & $31.74^{*}$ & $10.09^{*}$ & 0.85 & $50.70^{*}$ & $14.86^{*}$ \\
\hline & India & 1.86 & $33.50^{*}$ & $12.47^{*}$ & 1.23 & $34.27^{*}$ & 7.20 \\
\hline & Indonesia & 4.01 & $15.62^{*}$ & $9.63^{*}$ & 3.21 & $20.37^{*}$ & 7.29 \\
\hline & Japan & 5.54 & 4.36 & $26.34^{*}$ & 8.05 & 3.53 & 27.14 \\
\hline & Korea & 2.76 & $14.36^{*}$ & $13.19^{*}$ & 5.16 & $24.79^{*}$ & $52.84^{*}$ \\
\hline & Malaysia & $34.39^{*}$ & $15.19^{*}$ & 5.48 & $29.40^{*}$ & $19.65^{*}$ & 2.50 \\
\hline & New Zealand & 2.44 & $45.86^{*}$ & 3.21 & $9.71^{*}$ & $74.15^{*}$ & $18.19^{*}$ \\
\hline & Philippines & 8.71 & $16.10^{*}$ & $10.73^{*}$ & 6.15 & $19.97^{*}$ & 8.54 \\
\hline & Singapore & 1.12 & $43.18^{*}$ & 5.00 & 1.30 & $48.63^{*}$ & $9.52^{*}$ \\
\hline & Taiwan & $15.47^{*}$ & 8.95 & 6.12 & $24.48^{*}$ & $12.31^{*}$ & 4.21 \\
\hline & Thailand & 8.26 & $83.71^{*}$ & $13.74^{*}$ & $14.86^{*}$ & $98.12^{*}$ & $18.70^{*}$ \\
\hline
\end{tabular}

The first crisis indicators that we consider are related to debt conditions. There are actually three types of debt that we consider: (i) public, (ii) private and (iii) external debt. Our hypothesis is that high-debt countries should be more affected by a crisis than low-debt countries (see also Masson 1999; Briguglio et al. 2009; Reinhart and Rogoff 2010, 2011a, b). Tables 13 and 14 summarize the percentile of the gross public debt, domestic private credit, and external debt for 44 countries in 2006 and 2009, respectively. To investigate whether the debt is an important determinant in driving crisis, the selected 44 countries are classified into two groups of high-debt and lowdebt using the threshold of 80th percentile. ${ }^{11}$ Table 13 shows that if the gross public debt is selected as a crisis indicator, then high-debt countries (Japan, Greece, Italy, Belgium, Singapore, India, Argentina and Canada) will be more affected by contagion than the low-debt countries (Chile, Russia, Australia, Romania, China, New Zealand, Bulgaria and Ireland) during the subprime mortgage crisis and the Great Recession.

\footnotetext{
11 We also consider the 70th and 60th percentiles as the threshold for the high-debt countries and the 30th and 40th percentiles for the low-debt countries for the robustness check.
} 
Table 12 continued

\begin{tabular}{|c|c|c|c|c|c|c|c|}
\hline \multirow[t]{2}{*}{ Region } & \multirow[t]{2}{*}{ Recipient $(j)$} & \multicolumn{3}{|c|}{ Panel A: Contagion tests } & \multicolumn{3}{|c|}{ Panel B: Contagion tests } \\
\hline & & SMC & GRC & EDC & SMC & GRC & EDC \\
\hline \multirow[t]{22}{*}{ Europe } & Austria & 5.34 & $59.60^{*}$ & $12.91^{*}$ & 2.02 & $72.28^{*}$ & $11.14^{*}$ \\
\hline & Belgium & 1.03 & $110.57^{*}$ & 3.68 & 2.30 & $120.01^{*}$ & 5.11 \\
\hline & Bulgaria & $9.45^{*}$ & $31.58^{*}$ & $14.65^{*}$ & $11.13^{*}$ & $35.10^{*}$ & $14.75^{*}$ \\
\hline & Denmark & 0.72 & $58.53^{*}$ & 2.73 & 1.10 & $70.58^{*}$ & 1.46 \\
\hline & Finland & 8.93 & $56.95^{*}$ & 3.05 & 6.35 & $61.17^{*}$ & 3.86 \\
\hline & France & 0.95 & $57.16^{*}$ & $19.10^{*}$ & 1.38 & $66.71^{*}$ & $22.02^{*}$ \\
\hline & Germany & 6.19 & $53.62^{*}$ & 7.83 & 6.15 & $52.13^{*}$ & $10.01^{*}$ \\
\hline & Greece & 2.30 & $50.85^{*}$ & n.a. & 5.44 & $59.63^{*}$ & n.a. \\
\hline & Hungary & 9.17 & $35.79^{*}$ & $12.52^{*}$ & $15.52^{*}$ & $45.19^{*}$ & $16.36^{*}$ \\
\hline & Ireland & $20.47^{*}$ & $132.35^{*}$ & 4.20 & $20.39 *$ & $143.64^{*}$ & 6.63 \\
\hline & Italy & 0.34 & $80.75^{*}$ & 14.45 & 0.34 & $78.30^{*}$ & $19.58^{*}$ \\
\hline & Netherlands & 1.53 & $138.06^{*}$ & 9.40 & 4.28 & $145.94^{*}$ & $12.01^{*}$ \\
\hline & Norway & 5.54 & $90.22^{*}$ & 1.56 & 2.87 & $106.57^{*}$ & 0.25 \\
\hline & Poland & 1.89 & $53.52^{*}$ & $12.04^{*}$ & 4.11 & $62.91^{*}$ & $12.50^{*}$ \\
\hline & Portugal & 0.79 & $113.29^{*}$ & $91.49^{*}$ & 1.94 & $132.32^{*}$ & $129.63^{*}$ \\
\hline & Romania & 5.22 & $49.68^{*}$ & 188.93* & 6.66 & $51.88^{*}$ & $182.13^{*}$ \\
\hline & Russia & 7.75 & $87.75^{*}$ & $94.59^{*}$ & 8.92 & $81.76^{*}$ & $94.16^{*}$ \\
\hline & Spain & 1.31 & $83.93^{*}$ & $53.98^{*}$ & 0.30 & $81.49^{*}$ & $63.55^{*}$ \\
\hline & Sweden & 3.58 & $60.79^{*}$ & 2.88 & 2.65 & $65.80^{*}$ & 4.41 \\
\hline & Switzerland & 2.86 & $84.79^{*}$ & $14.45^{*}$ & 1.77 & $97.76^{*}$ & $14.69^{*}$ \\
\hline & Turkey & 4.06 & $66.27^{*}$ & $130.59^{*}$ & $9.55^{*}$ & $97.47^{*}$ & $120.92 *$ \\
\hline & UK & 5.24 & $87.20^{*}$ & $12.33^{*}$ & 0.55 & $116.85^{*}$ & $18.92^{*}$ \\
\hline
\end{tabular}

*Significance of contagion at the 5\% level. SMC denotes the subprime mortgage crisis, GRC denotes the Great Recession, and EDC denotes the European debt crisis. Panel A is based on the pre-crisis period from January 1, 2005 to June 25, 2007; while Panel B is from January 1, 2005 to August 25, 2007

The second crisis indicator that we consider is related to fiscal and current account balances. We hypothesize that, if a country has a larger either fiscal deficit or current account deficit, the probability it will suffer from a crisis will be higher (see also Burnside 2004; Edward, 2006; Rose and Spiegel 2012; and Manasse and Zavalloni 2013). Tables 15 and 16 present the percentile of the fiscal account balance, current account balance and both account balance for 44 countries in 2006 and 2009, respectively. To investigate whether fiscal and current account balances can be treated as an early warning indicator of financial crisis, the selected 44 countries are also classified into two groups of weak and strong using threshold of the 80th percentiles. Table 15 shows that if the fiscal account balance is selected as a facilitator of contagion, then countries with weak fiscal account balance (Hungary, India, Greece, Portugal, Japan, Poland, Brazil and Italy) will be more affected by contagion than the countries with strong account balance (Norway, Russia, Chile, Singapore, Denmark, New Zealand, Hong Kong and Finland) during the subprime mortgage crisis and the Great Recession. 
Table 13 Gross government debt, domestic private credit and external debt for 44 countries in 2006 (prior to the Subprime mortgage crisis), expressed as a percentage of GDP.

\begin{tabular}{|c|c|c|c|c|c|c|}
\hline \multirow[t]{2}{*}{ Percentile } & \multicolumn{2}{|l|}{ Public debt } & \multicolumn{2}{|l|}{ Private debt } & \multicolumn{2}{|l|}{ External debt } \\
\hline & Country & $\%$ & Country & $\%$ & Country & $\%$ \\
\hline 100th & Japan & 186.00 & USA & 197.68 & Ireland & 696.70 \\
\hline 100th & Greece & 107.47 & Poland & 196.22 & UK & 329.38 \\
\hline 100th & Italy & 106.35 & Canada & 194.19 & Netherlands & 286.69 \\
\hline 100th & Belgium & 87.95 & Japan & 188.69 & Belgium & 264.33 \\
\hline 90th & Singapore & 86.39 & Denmark & 185.68 & Switzerland & 259.77 \\
\hline 90th & India & 77.11 & Ireland & 181.20 & Hong Kong & 257.86 \\
\hline 90th & Argentina & 76.44 & UK & 168.10 & Austria & 185.69 \\
\hline 90th & Canada & 70.26 & Netherlands & 167.19 & Sweden & 185.28 \\
\hline 80th & Germany & 67.92 & Spain & 166.98 & Portugal & 181.36 \\
\hline 80th & Brazil & 66.96 & Switzerland & 163.69 & Singapore & 177.12 \\
\hline 80th & Hungary & 65.91 & S. Africa & 163.37 & Denmark & 173.99 \\
\hline 80th & France & 64.08 & Portugal & 151.90 & France & 172.97 \\
\hline 70th & USA & 63.77 & Hong Kong & 136.80 & Germany & 135.81 \\
\hline 70th & Portugal & 63.69 & Korea & 135.24 & Spain & 131.24 \\
\hline 70th & Switzerland & 62.36 & New Zealand & 130.98 & Finland & 120.19 \\
\hline 70th & Austria & 62.31 & Austria & 116.37 & Norway & 117.06 \\
\hline 60th & Norway & 58.72 & Australia & 114.13 & Greece & 116.52 \\
\hline 60th & Philippines & 51.58 & Sweden & 112.81 & New Zealand & 111.82 \\
\hline 60th & Poland & 47.74 & China & 110.73 & Italy & 103.62 \\
\hline 60th & Netherlands & 47.37 & Germany & 109.60 & Hungary & 88.65 \\
\hline 60th & Turkey & 46.52 & Malaysia & 103.66 & Australia & 83.07 \\
\hline 60th & Sweden & 45.27 & France & 98.43 & USA & 76.23 \\
\hline 50th & UK & 42.76 & Thailand & 95.20 & Bulgaria & 70.69 \\
\hline 50th & Thailand & 41.99 & Italy & 94.47 & Canada & 61.44 \\
\hline 50th & Malaysia & 41.54 & Norway & 86.19 & Argentina & 57.73 \\
\hline 50th & Spain & 39.68 & Singapore & 86.02 & Philippines & 47.78 \\
\hline 50th & Finland & 39.63 & Greece & 85.24 & Poland & 44.91 \\
\hline 50th & Indonesia & 38.99 & & & Romania & 39.61 \\
\hline 40th & Mexico & 37.80 & Belgium & 82.03 & Turkey & 37.00 \\
\hline 40th & Colombia & 36.78 & Finland & 78.80 & Indonesia & 35.87 \\
\hline 40th & Taiwan & 34.20 & Chile & 77.69 & Japan & 35.19 \\
\hline 40th & Peru & 33.10 & Hungary & 55.60 & Malaysia & 33.41 \\
\hline 30th & S. Africa & 32.63 & Bulgaria & 44.91 & Thailand & 32.68 \\
\hline 30th & Denmark & 32.08 & India & 43.22 & Peru & 31.73 \\
\hline 30th & Korea & 31.12 & Brazil & 40.34 & Chile & 31.40 \\
\hline
\end{tabular}


Table 13 continued

\begin{tabular}{|c|c|c|c|c|c|c|}
\hline \multirow[t]{2}{*}{ Percentile } & \multicolumn{2}{|l|}{ Public debt } & \multicolumn{2}{|l|}{$\underline{\text { Private debt }}$} & \multicolumn{2}{|c|}{$\underline{\text { External debt }}$} \\
\hline & Country & $\%$ & Country & $\%$ & Country & $\%$ \\
\hline 30th & Hong Kong & 31.04 & Colombia & 33.36 & Russia & 29.18 \\
\hline 20th & Ireland & 24.60 & Russia & 32.48 & Colombia & 23.15 \\
\hline 20 th & Bulgaria & 23.41 & Philippines & 28.69 & Taiwan & 23.09 \\
\hline 20th & New Zealand & 19.29 & Turkey & 25.94 & Korea & 21.15 \\
\hline 20th & China & 16.19 & Romania & 25.87 & S. Africa & 20.29 \\
\hline 10th & Romania & 12.62 & Indonesia & 24.61 & Mexico & 18.06 \\
\hline 10th & Australia & 10.01 & Mexico & 19.38 & India & 16.00 \\
\hline 10 th & Russia & 9.05 & Peru & 17.05 & Brazil & 15.10 \\
\hline 10th & Chile & 4.99 & Argentina & 13.03 & China & 11.50 \\
\hline
\end{tabular}

The data for gross government debt is collected from IMF, World Economic Outlook Database. The data for domestic credit and external debt is collected from Datastream

Table 14 Gross government debt, domestic private credit and external debt for 44 countries in 2009 (prior to the European debt crisis), expressed as a percentage of GDP

\begin{tabular}{|c|c|c|c|c|c|c|}
\hline \multirow[t]{2}{*}{ Percentile } & \multicolumn{2}{|l|}{ Public debt } & \multicolumn{2}{|l|}{ Private debt } & \multicolumn{2}{|l|}{ External debt } \\
\hline & Country & $\%$ & Country & $\%$ & Country & $\%$ \\
\hline 100 & Japan & 210.25 & Poland & 433.57 & Ireland & 1107.06 \\
\hline 100 & Greece & 129.69 & Ireland & 232.10 & UK & 398.20 \\
\hline 100 & Italy & 116.42 & Denmark & 223.87 & Hong Kong & 320.56 \\
\hline 100 & Singapore & 101.49 & Netherlands & 214.15 & Belgium & 317.14 \\
\hline 90 & Belgium & 95.69 & Spain & 212.35 & Netherlands & 302.08 \\
\hline 90 & USA & 86.32 & UK & 210.28 & Switerland & 245.00 \\
\hline 90 & Portugal & 83.70 & USA & 196.33 & Singapore & 229.97 \\
\hline 90 & Canada & 81.28 & Portugal & 186.78 & Portugal & 217.85 \\
\hline 80 & Hungary & 79.79 & Japan & 183.44 & Sweden & 213.38 \\
\hline 80 & France & 79.19 & Switzerland & 168.81 & Austria & 212.80 \\
\hline 80 & Germany & 74.51 & Korea & 156.29 & Denmark & 191.31 \\
\hline 80 & India & 75.53 & Hong Kong & 155.43 & France & 89.45 \\
\hline 70 & Austria & 69.17 & S. Africa & 152.08 & Greece & 173.65 \\
\hline 70 & UK & 67.09 & New Zealand & 145.51 & Spain & 165.08 \\
\hline 70 & Brazil & 66.82 & Sweden & 136.23 & Norway & 158.83 \\
\hline 70 & Ireland & 64.42 & Canada & 128.25 & Finland & 155.95 \\
\hline 60 & Netherlands & 60.76 & China & 127.19 & Germany & 152.32 \\
\hline 60 & Argentina & 58.70 & Austria & 126.00 & Hungary & 144.88 \\
\hline 60 & Spain & 53.98 & Australia & 123.21 & New Zealand & 135.40 \\
\hline 60 & Malaysia & 52.81 & Thailand & 116.42 & Italy & 118.10 \\
\hline 60 & Poland & 50.88 & Germany & 113.42 & Bulgaria & 106.58 \\
\hline 60 & Switzerland & 49.79 & Malaysia & 111.61 & USA & 94.14 \\
\hline 50 & Norway & 48.99 & France & 111.55 & Australia & 89.24 \\
\hline
\end{tabular}


Table 14 continued

\begin{tabular}{|c|c|c|c|c|c|c|}
\hline \multirow[t]{2}{*}{ Percentile } & \multicolumn{2}{|l|}{ Public debt } & \multicolumn{2}{|l|}{$\underline{\text { Private debt }}$} & \multicolumn{2}{|c|}{$\underline{\text { External debt }}$} \\
\hline & Country & $\%$ & Country & $\%$ & Country & $\%$ \\
\hline 50 & Turkey & 46.07 & Italy & 110.97 & Canada & 77.63 \\
\hline 50 & Thailand & 45.22 & Singapore & 99.59 & Romania & 69.09 \\
\hline 50 & Philippines & 44.34 & Belgium & 97.49 & Poland & 59.57 \\
\hline 50 & Mexico & 43.94 & Greece & 94.28 & Turkey & 46.37 \\
\hline 50 & Finland & 43.52 & & & Japan & 42.47 \\
\hline 40 & Sweden & 42.56 & Finland & 93.89 & Argentina & 41.22 \\
\hline 40 & Denmark & 40.68 & Noway & 86.19 & Korea & 39.42 \\
\hline 40 & Taiwan & 38.01 & Bulgaria & 75.50 & Chile & 39.38 \\
\hline 40 & Colombia & 36.15 & Chile & 70.69 & Russia & 38.52 \\
\hline 30 & Korea & 33.77 & Hungary & 69.51 & Malaysia & 34.28 \\
\hline 30 & S. Africa & 31.34 & Brazil & 48.87 & Philippines & 33.93 \\
\hline 30 & Hong Kong & 31.18 & India & 47.30 & Indonesia & 29.97 \\
\hline 30 & Indonesia & 28.64 & Russia & 46.15 & Peru & 29.41 \\
\hline 20 & Peru & 27.13 & Romania & 46.15 & Thailand & 27.67 \\
\hline 20 & New Zealand & 25.88 & Colombia & 39.96 & S. Africa & 25.78 \\
\hline 20 & Romania & 23.79 & Turkey & 36.48 & Colombia & 22.69 \\
\hline 20 & China & 17.67 & Philippines & 29.16 & Mexico & 22.65 \\
\hline 10 & Australia & 16.81 & Indonesia & 27.66 & Taiwan & 21.67 \\
\hline 10 & Bulgaria & 15.58 & Peru & 23.63 & India & 19.53 \\
\hline 10 & Russia & 10.96 & Mexico & 22.77 & Brazil & 12.39 \\
\hline 10 & Chile & 5.83 & Argentina & 13.53 & China & 8.60 \\
\hline
\end{tabular}

The data for gross government debt is collected from IMF, World Economic Outlook Database. The data for domestic credit and external debt is collected from Datastream

The third crisis indicator that we consider is related to regional linkages. If a country's location has an economically relevant form of geographically proximity to the country in which the crisis originates, then we hypothesize that the country would be more likely affected by the crisis than others (see also Fry-McKibbin et al. 2014). Therefore, it is expected that the North and South American countries should be more affected by the US-sourced crises (subprime mortgage crisis and the Great Recession crisis) and European countries more affected by the Greek-sourced crisis (European debt crisis).

The last crisis indicator that we consider is related to a country's level of economic development. If there is a crisis in a developed/emerging country, it is hypothesized that other developed/emerging countries should be more likely to experience contagion than others. The development comparability indicator reflects similar characteristics for countries with similar market fundamentals, political environment and financial liberalization to the country in which the crisis originates (Goldstein 1998; Fry-McKibbin et al.2014). To investigate whether development comparability indicator can be treated 
Table 15 Fiscal account balance, current account balance and both account balance for 44 countries in 2006 (prior to the Subprime mortgage crisis), expressed as a percentage of GDP

\begin{tabular}{|c|c|c|c|c|c|c|}
\hline \multirow[t]{2}{*}{ Percentile } & \multicolumn{2}{|c|}{ Fiscal account balance } & \multicolumn{2}{|c|}{ Current account balance } & \multicolumn{2}{|c|}{ Both account balance } \\
\hline & Country & $\%$ & Country & $\%$ & Country & $\%$ \\
\hline 100th & Hungary & -9.37 & Bulgaria & -17.56 & Greece & -17.41 \\
\hline 100th & India & -6.17 & Greece & -11.39 & Hungary & -16.77 \\
\hline 100th & Greece & -6.02 & Portugal & -10.69 & Portugal & -14.44 \\
\hline 100th & Portugal & -3.75 & Romania & -10.39 & Bulgaria & -14.22 \\
\hline 90th & Japan & -3.65 & Spain & -8.96 & Romania & -11.74 \\
\hline 90th & Poland & -3.63 & New Zealand & -8.28 & USA & -7.73 \\
\hline 90th & Brazil & -3.54 & Hungary & -7.41 & Poland & -7.48 \\
\hline 90th & Italy & -3.41 & Turkey & -6.00 & India & -7.18 \\
\hline 80th & UK & -2.76 & USA & -5.76 & Turkey & -6.69 \\
\hline 80th & Malaysia & -2.73 & Australia & -5.33 & Spain & -6.59 \\
\hline 80th & France & -2.38 & S. Africa & -5.31 & UK & -5.60 \\
\hline 80th & Taiwan & -2.02 & Poland & -3.85 & Italy & -4.91 \\
\hline 70 th & USA & -1.97 & Ireland & -3.55 & New Zealand & -4.15 \\
\hline 70th & Austria & -1.68 & UK & -2.84 & S. Africa & -4.11 \\
\hline 70 th & Germany & -1.65 & Colombia & -1.86 & Australia & -3.56 \\
\hline 70 th & Romania & -1.35 & Italy & -1.50 & France & -2.95 \\
\hline 60th & Argentina & -1.07 & India & -1.01 & Colombia & -2.85 \\
\hline 60 th & Colombia & -0.99 & Mexico & -0.77 & Brazil & -2.28 \\
\hline 60 th & Mexico & -0.98 & France & -0.58 & Mexico & -1.75 \\
\hline 60 th & Turkey & -0.69 & thailand & 1.12 & Ireland & -0.63 \\
\hline 60 th & China & -0.68 & Brazil & 1.25 & Japan & 0.27 \\
\hline 60th & Philippines & -0.05 & Canada & 1.37 & Austria & 1.13 \\
\hline 50 th & Indonesia & 0.23 & Korea & 1.48 & Belgium & 2.17 \\
\hline 50th & Belgium & 0.31 & Belgium & 1.86 & Argentina & 2.31 \\
\hline 50 th & Netherlands & 0.52 & Indonesia & 2.62 & Korea & 2.62 \\
\hline 50 th & Switzerland & 0.94 & Austria & 2.80 & Indonesia & 2.85 \\
\hline 50 th & Korea & 1.14 & Denmark & 2.98 & Canada & 3.16 \\
\hline 50th & S. Africa & 1.20 & Peru & 3.16 & thailand & 3.30 \\
\hline 40th & Australia & 1.77 & Argentina & 3.37 & Philippines & 4.32 \\
\hline 40th & Canada & 1.80 & Japan & 3.92 & Germany & 4.60 \\
\hline 40th & Peru & 1.92 & Finland & 4.16 & Taiwan & 4.97 \\
\hline 40th & thailand & 2.19 & Philippines & 4.37 & Peru & 5.08 \\
\hline 30th & Sweden & 2.22 & Chile & 4.60 & China & 7.87 \\
\hline 30th & Spain & 2.37 & Germany & 6.26 & Denmark & 8.02 \\
\hline 30 th & Ireland & 2.93 & Taiwan & 6.99 & Finland & 8.24 \\
\hline 30th & Bulgaria & 3.34 & China & 8.55 & Netherlands & 9.85 \\
\hline 20th & Finland & 4.08 & Sweden & 8.68 & Sweden & 10.90 \\
\hline
\end{tabular}


Table 15 continued

\begin{tabular}{|c|c|c|c|c|c|c|}
\hline \multirow[t]{2}{*}{ Percentile } & \multicolumn{2}{|c|}{ Fiscal account balance } & \multicolumn{2}{|c|}{ Current account balance } & \multicolumn{2}{|c|}{ Both account balance } \\
\hline & Country & $\%$ & Country & $\%$ & Country & $\%$ \\
\hline 20th & Hong Kong & 4.11 & Russia & 9.33 & Chile & 12.05 \\
\hline 20th & New Zealand & 4.13 & Netherlands & 9.33 & Malaysia & 13.37 \\
\hline 20th & Denmark & 5.04 & Hong Kong & 11.85 & Switzerland & 15.29 \\
\hline 10th & Singapore & 7.11 & Switzerland & 14.35 & Hong Kong & 15.96 \\
\hline 10th & Chile & 7.45 & Malaysia & 16.09 & Russia & 17.65 \\
\hline 10th & Russia & 8.33 & Norway & 16.40 & Singapore & 31.89 \\
\hline 10th & Norway & 18.30 & Singapore & 24.78 & Norway & 34.70 \\
\hline
\end{tabular}

The data is collected from IMF, World Economic Outlook Database. Both account balance consists of fiscal and current account balance

Table 16 Fiscal account balance, current account balance and both account balance for 44 countries in 2009 (prior tothe European debt crisis), expressed as a percentage of GDP

\begin{tabular}{|c|c|c|c|c|c|c|}
\hline \multirow[t]{2}{*}{ Percentile } & \multicolumn{2}{|c|}{ Fiscal account balance } & \multicolumn{2}{|c|}{ Current account balance } & \multicolumn{2}{|c|}{$\underline{\text { Both account balance }}$} \\
\hline & Country & $\%$ & Country & $\%$ & Country & $\%$ \\
\hline 100th & Ireland & -13.78 & Greece & -11.17 & Greece & -26.78 \\
\hline 100th & Greece & -15.61 & Portugal & -10.92 & Portugal & -21.09 \\
\hline 100th & USA & -12.93 & Bulgaria & -8.93 & Ireland & -16.10 \\
\hline 100th & UK & -11.25 & Spain & -4.83 & Spain & -16.02 \\
\hline 90th & Spain & -11.19 & Australia & -4.25 & US & -15.58 \\
\hline 90th & Japan & -10.39 & Romania & -4.03 & UK & -12.67 \\
\hline 90th & Portugal & -10.17 & S. Africa & -4.03 & India & -12.55 \\
\hline 90th & India & -9.75 & Poland & -3.98 & Romania & -11.43 \\
\hline 80th & France & -7.56 & Canada & -2.92 & Poland & -11.38 \\
\hline 80th & Poland & -7.41 & India & -2.80 & Bulgaria & -9.84 \\
\hline 80th & Romania & -7.27 & USA & -2.65 & S. Africa & -9.57 \\
\hline 80th & Russia & -6.31 & New Zealand & -2.47 & France & -8.90 \\
\hline 70th & Taiwan & -6.18 & Ireland & -2.32 & Australia & -8.84 \\
\hline 70th & Malaysia & -6.16 & Colombia & -2.14 & Turkey & -7.97 \\
\hline 70th & Turkey & -5.99 & Italy & -1.99 & Japan & -7.48 \\
\hline 70th & Belgium & -5.64 & Turkey & -1.98 & Canada & -7.44 \\
\hline 60th & Netherlands & -5.61 & Brazil & -1.50 & Italy & -7.41 \\
\hline 60th & S. Africa & -5.53 & UK & -1.42 & Belgium & -7.05 \\
\hline 60th & Italy & -5.43 & Belgium & -1.41 & Mexico & -5.94 \\
\hline 60th & Mexico & -5.08 & France & -1.33 & Colombia & -4.94 \\
\hline 60th & Australia & -4.58 & Mexico & -0.86 & Hungary & -4.77 \\
\hline 60th & Hungary & -4.55 & Peru & -0.57 & Brazil & -4.59 \\
\hline 50th & Canada & -4.52 & Hungary & -0.22 & New Zealand & -4.01 \\
\hline 50th & Austria & -4.12 & Finland & 1.76 & Russia & -2.19 \\
\hline
\end{tabular}


Table 16 continued

\begin{tabular}{|c|c|c|c|c|c|c|}
\hline \multirow[t]{2}{*}{ Percentile } & \multicolumn{2}{|c|}{ Fiscal account balance } & \multicolumn{2}{|c|}{ Current account balance } & \multicolumn{2}{|c|}{$\underline{\text { Both account balance }}$} \\
\hline & Country & $\%$ & Country & $\%$ & Country & $\%$ \\
\hline 50 th & Chile & -4.09 & Indonesia & 1.97 & Peru & -2.07 \\
\hline 50th & Argentina & -3.61 & Chile & 2.05 & Chile & -2.04 \\
\hline 50th & thailand & -3.18 & Argentina & 2.47 & Austria & -1.41 \\
\hline 50 th & Brazil & -3.09 & Austria & 2.71 & Argentina & -1.14 \\
\hline 40th & Germany & -3.08 & Japan & 2.91 & Finland & -0.96 \\
\hline 40th & China & -3.06 & Denmark & 3.40 & Netherlands & -0.43 \\
\hline 40th & Colombia & -2.79 & Korea & 3.93 & Indonesia & 0.21 \\
\hline 40th & Denmark & -2.77 & Russia & 4.12 & Denmark & 0.63 \\
\hline 30th & Finland & -2.72 & China & 4.87 & China & 1.81 \\
\hline 30th & Philippines & -2.62 & Netherlands & 5.18 & Germany & 2.89 \\
\hline 30th & Indonesia & -1.76 & Philippines & 5.55 & Philippines & 2.93 \\
\hline 30th & New Zealand & -1.54 & Germany & 5.96 & Korea & 3.95 \\
\hline 20th & Peru & -1.50 & Sweden & 6.27 & Thailand & 5.13 \\
\hline 20th & Sweden & -0.98 & thailand & 8.30 & Taiwan & 5.19 \\
\hline 20th & Bulgaria & -0.92 & Hong Kong & 8.39 & Sweden & 5.29 \\
\hline 20th & Singapore & -0.47 & Switzerland & 10.55 & Malaysia & 9.37 \\
\hline 10 th & Korea & 0.02 & Taiwan & 11.37 & Hong Kong & 9.86 \\
\hline 10th & Switzerland & 0.51 & Norway & 11.72 & Switzerland & 11.06 \\
\hline 10 th & Hong Kong & 1.47 & Malaysia & 15.53 & Singapore & 17.27 \\
\hline 10 th & Norway & 10.53 & Singapore & 17.73 & Norway & 22.26 \\
\hline
\end{tabular}

The data is collected from IMF, World Economic Outlook Database. Both account balance consists of fiscal and current account balance

as an early warning indicator of financial crisis, the selected 44 countries are classified into two groups of developed and emerging countries. ${ }^{12}$

The market capitalization (cap) weight is summarized in Table 17 in order to calculate the crisis severity index. The table shows the percentages of total market cap for 43 countries in 2006 and 2009 (prior to the crisis) and illustrates that the crisis severity index is mainly dominated by Japan (14.67\%), the UK $(11.78 \%)$ and France (7.54\%) in 2006, and mainly dominated by the USA (33\%), China (10.96\%) and Japan $(7.39 \%)$ in 2009.

\footnotetext{
12 Developed countries in the Americas region include: Canada, Chile and Mexico. Emerging countries in the Americas region include: Argentina, Brazil, Colombia and Peru. Developed countries in the European region include: Austria, Belgium, Denmark, Finland, France, Germany, Hungary, Ireland, Italy, Netherlands, Norway, Portugal, Spain, Sweden, Switzerland, Turkey and the UK. Emerging countries in the European region include: Bulgaria, Poland, Romania and Russia.
} 
Table 17 The total market capitalization and percentage of total market capitalization for 44 countries in 2006 (prior to the Subprime mortgage crisis and the Great Recession) and 2009 (prior to the European debt crisis)

\begin{tabular}{|c|c|c|c|c|c|}
\hline \multirow[t]{2}{*}{ Region } & \multirow[t]{2}{*}{ Country } & \multicolumn{2}{|c|}{ Total market capitalization } & \multicolumn{2}{|c|}{$\%$ of total } \\
\hline & & 2006 & 2009 & 2006 & 2009 \\
\hline Africa & S. Africa & 715,025 & 704,822 & 2.22 & 1.54 \\
\hline \multirow[t]{8}{*}{ Americas } & Argentina & 79,730 & 48,932 & 0.25 & 0.11 \\
\hline & Brazil & 711,100 & $1,167,335$ & 2.21 & 2.55 \\
\hline & Canada & $1,700,708$ & $1,680,958$ & 5.28 & 3.68 \\
\hline & Chile & 174,556 & 209,475 & 0.54 & 0.46 \\
\hline & Colombia & 56,204 & 133,301 & 0.17 & 0.29 \\
\hline & Mexico & 348,345 & 340,565 & 1.08 & 0.75 \\
\hline & Peru & 59,658 & 69,753 & 0.19 & 0.15 \\
\hline & USA & $19,425,855$ & $15,077,286$ & - & 33.00 \\
\hline \multirow[t]{13}{*}{ Asia } & Australia & $1,095,858$ & $1,258,456$ & 3.40 & 2.75 \\
\hline & China & $2,426,326$ & $5,007,646$ & 7.53 & 10.96 \\
\hline & Hong Kong & 895,249 & 915,825 & 2.78 & 2.00 \\
\hline & India & 818,879 & $1,179,235$ & 2.54 & 2.58 \\
\hline & Indonesia & 138,886 & 178,191 & 0.43 & 0.39 \\
\hline & Japan & $4,726,269$ & $3,377,892$ & 14.67 & 7.39 \\
\hline & Korea & 835,188 & 836,462 & 2.59 & 1.83 \\
\hline & Malaysia & 235,356 & 255,952 & 0.73 & 0.56 \\
\hline & New Zealand & 44,940 & 67,061 & 0.14 & 0.15 \\
\hline & Philippines & 68,382 & 80,132 & 0.21 & 0.18 \\
\hline & Singapore & 276,329 & 310,766 & 0.86 & 0.68 \\
\hline & Taiwan & 594,659 & 658,991 & 1.85 & 1.44 \\
\hline & Thailand & 141,093 & 138,189 & 0.44 & 0.30 \\
\hline \multirow[t]{13}{*}{ Europe } & Austria & 191,300 & 53,578 & 0.59 & 0.12 \\
\hline & Belgium & 396,220 & 261,429 & 1.23 & 0.57 \\
\hline & Bulgaria & 10,325 & 7,103 & 0.03 & 0.02 \\
\hline & Denmark & 231,015 & 186,852 & 0.72 & 0.41 \\
\hline & Finland & 265,477 & 91,021 & 0.82 & 0.20 \\
\hline & France & $2,428,572$ & $1,972,040$ & 7.54 & 4.32 \\
\hline & Germany & $1,637,826$ & $1,297,568$ & 5.08 & 2.84 \\
\hline & Greece & 208,284 & 54,717 & 0.65 & - \\
\hline & Hungary & 41,935 & 28,288 & 0.13 & 0.06 \\
\hline & Ireland & 163,358 & 61,291 & 0.51 & 0.13 \\
\hline & Italy & $1,026,640$ & 317,317 & 3.19 & 0.69 \\
\hline & Netherlands & 779,645 & 542,533 & 2.42 & 1.19 \\
\hline & Norway & 281,081 & 227,233 & 0.87 & 0.50 \\
\hline
\end{tabular}


Table 17 continued

\begin{tabular}{lllllll}
\hline Region & Country & \multicolumn{2}{l}{ Total market capitalization } & & \multicolumn{2}{l}{$\%$ of total } \\
\cline { 3 - 3 } \cline { 5 - 6 } & 2006 & 2009 & & 2006 & 2009 \\
\hline Poland & 149,054 & 135,277 & & 0.46 & 0.30 \\
Portugal & 104,201 & 98,650 & & 0.32 & 0.22 \\
Romania & 32,784 & 30,325 & & 0.10 & 0.07 \\
Russia & $1,057,189$ & 861,424 & & 3.28 & 1.89 \\
Spain & $1,323,090$ & $1,297,227$ & & 4.11 & 2.84 \\
Sweden & 573,250 & 432,296 & & 1.78 & 0.95 \\
Switzerland & $1,212,508$ & $1,070,694$ & & 3.76 & 2.34 \\
Turkey & 162,399 & 225,735 & & 0.50 & 0.49 \\
UK & $3,794,310$ & $2,796,444$ & 11.78 & 6.12
\end{tabular}

The total market capitalization are reported as millions of US dollars. The data is collected from the World Bank of world development indicator. The US and Greece are not listed for the weight of market capitalization because they are selected as the country in which the crisis originates

\section{References}

Ahlgren N, Antell J (2010) Stock market linkages and financial contagion: a cobreaking analysis. Q Rev Econ Finance 50:157-66

Akhtaruzzaman M, Boubaker S, Sensoy A (2021) Financial contagion during COVID-19 crisis. Finance Res Lett 38:101604

Bai J, Perron P (2003) Computation and analysis of multiple structural change models. J Appl Econom 18:1-22

Bae K, Karolyi G, Stulz R (2003) A new approach to measuring financial contagion. Rev Financ Stud 16(3):717-63

Beirne J, Fratzscher M (2013) The pricing of sovereign risk and contagion during the European sovereign debt crisis. J Int Money Finance 34:60-82

Bekaert G, Ehrman M, Fratzscher M, Mehl A (2011) Global crises and equity market contagion. In: NBER working paper No. 17121

Briguglio L, Cordina G, Farrugia N, Vella S (2009) Economic vulnerability and resilience: concepts and measurements. Oxf Dev Stud 37(3):229-47

Burnside C (2004) Currency crises and contingent liabilities. J Int Econ 62(1):25-52

Caramazza F, Ricci L, Salgado R (2004) International financial contagion in currency crises. J Int Money Finance 23(1):51-70

Chan JCC, Fry-McKibbin RA, Hsiao CY (2019) A regime switching skew-normal model of contagion. Stud Nonlinear Dyn Econom 23(1):1-24

Cipriani M, Gardenal G, Guarino A (2013) Financial contagion in the laboratory: the cross-market rebalancing channel. J Bank Finance 37:4310-26

Cobb L, Koppstein P, Chen NH (1983) Estimation and moment recursion relations for multimodal distributions of the exponential family. J Am Stat Assoc 78(381):124-30

de Haas R, van Horen N (2013) Running for the exit? International bank lending during a financial crisis. Rev Financ Stud 26(1):244-85

Didier T, Inessa L, Maria SMP (2010) What explains stock markets' vulnerability to the 2007-2008 crisis? In: Policy research working paper 5224, World Bank, Latin America \& Caribbean Region

Dioikitopoulos EV (2018) Dynamic adjustment of fiscal policy under a debt crisis. J Econ Dyn Control 93:260-76

Dungey M, Fry RA, Gonzalez-Hermosillo B, Martin VL, Tang C (2009) Are financial crises alike? In: IMF working paper WP/10/14

Dungey M, Martin VL (2007) Unravelling financial market linkages during crises. J Appl Econom 22:89_ 119 
Edwards S (2006) The US current account deficit: gradual correction or abrupt adjustment? J Policy Model 28:629-43

Ehrmann M, Fratzscher M, Mehl A (2009) What has made the current financial crisis truly global? In: ECB working paper

Favero CA, Giavazzi F (2002) Is the international propagation of financial shocks non-linear? Evidence from the ERM. J Int Econ 57(1):231-46

Finta MA, Frijns B, Tourani-Rad A (2019) Time-varying contemporaneous spillovers during the European debt crisis. Empir Econ 57(2):423-48

Forbes KJ (2012) The Big C: identifying contagion. In: NBER working paper No. 18465

Forbes KJ, Rigobon R (2002) No contagion, only interdependence: measuring stock market co-movements. J Finance 57(5):2223-61

Fry RA, Martin VL, Tang C (2010) A new class of tests of contagion with applications. J Bus Econ Stat 28:423-37

Fry-McKibbin RA, Hsiao CY (2018) Extremal Dependence Tests of Contagion. Econometric Reviews 37(6):626-649

Fry-McKibbin RA, Hsiao CY, Martin VL (2019) Joint Tests of Contagion with Applications. Quantitative Finance 19(3):473-90

Fry-McKibbin RA, Hsiao CY, Martin VL (2021) Measuring financial interdependence in asset markets with an application to eurozone equities. J Bank Finance 12:105985

Fry-McKibbin RA, Hsiao CY, Tang C (2014) Contagion and Global Financial Crises: Lessons from Nine Crisis Episodes. Open Economics Review 25(3):521-70

Garcia R, Tsafack G (2011) Dependence structure and extreme comovements in international equity and bond markets. J Bank Finance 35(8):1954-70

Giordano R, Pericoli M, Tommasino P (2013) Pure or Wake-up-call Contagion? Another Look at the EMU Sovereign Debt Crisis, International Finance 16(2):131-60

Glick R, Rose A (1999) Contagion and trade: why are currency crises regional? J Int Money Finance 18(4):603-17

Goldstein M (1998) The Asian financial crisis: causes, curses and systemic implications, policy analysis in international economics, 55, Institute for International Economics, Washington, DC

Gravelle T, Kichian M, Morley J (2006) Detecting Shift-Contagion in Currency and Bond Markets. J Int Econ 68:409-23

Kali R, Reyes J (2010) Financial contagion on the international trade network. Econ Inq 48(4):1072-101

Keddad B, Schalck C (2020) Evaluating sovereign risk spillovers on domestic banks during the European debt crisis. Econ Model 88:356-75

King MA, Wadhwani S (1990) Transmission of volatility between stock markets. Rev Financ Stud 3(1):5-33

Lye JN, Martin VL (1993) Robust estimation, non-normalities and generalized exponential distributions. J Am Stat Assoc 88:253-59

Manasse P, Zavalloni L (2013) Sovereign contagion in Europe: evidence from the CDS Market. In: IGIER working paper No. 471

Masson P (1999) Contagion: macroeconomic models with multiple equilibria. J Int Money Finance 18(4):587-602

Matsuyama K (2007) Credit traps and credit cycles. Am Econ Rev 97(1):503-16

Morley J (2016) Macro-finance linkages. J Econ Surveys 30(4):698-711

Niemann S, Pichler P (2020) Optimal fiscal policy and sovereign debt crises. Rev Econ Dyn (forthcoming)

Niţoi M, Pochea MM (2020) Time-varying dependence in European equity markets: a contagion and investor sentiment driven analysis. Econ Model 86:133-47

Pesaran H, Pick A (2007) Econometric issues in the analysis of contagion. J Econ Dyn Control 31(4):124577

Reinhart C, Rogoff K (2010) Growth in a time of debt. Am Econ Rev 100(2):573-78

Reinhart C, Rogoff K (2011) From financial crash to debt crisis. Am Econ Rev 1676-1706

Reinhart C, Rogoff K (2011) A decade of debt. In: NBER working paper No. 16827

Rodriguez JC (2007) Measuring financial contagion: a copula approach. J Empir Finance 14(3):401-23

Rose AK, Spiegel MM (2012) Cross-country causes and consequences of the 2008 crisis: early warning. Jpn World Econ 24(1):1-16

Samarakoon LP (2017) Contagion of the Eurozone debt crisis. J Int Financ Mark Inst Money 49:115-28

Silvapulle P, Fenech JP, Thomas A, Brooks R (2016) Determinants of sovereign bond yield spreads and contagion in the peripheral EU countries. Econ Model 58:83-92 
Ters K, Urban J (2018) Intraday dynamics of credit risk contagion before and during the euro area sovereign debt crisis: evidence from central europe. Int Rev Econ Finance 54:123-42

Van Rijckeghem C, Weder B (2001) Sources of contagion: is it finance or trade? J Int Econ 54(2):293-308

Publisher's Note Springer Nature remains neutral with regard to jurisdictional claims in published maps and institutional affiliations. 